\title{
Magnetic field effects on plant growth, development, and evolution
}

\author{
Massimo E. Maffei * \\ Department of Life Sciences and Systems Biology, Innovation Centre, University of Turin, Turin, Italy
}

\section{Edited by:}

Franck Anicet Ditengou, University of Freiburg, Germany

Reviewed by:

Taras P. Pasternak, Inst. Biologie II, Germany

Maikel Christian Rheinstadter, McMaster University, Canada

*Correspondence:

Massimo E. Maffei, Department Life

Sciences and Systems Biology,

Plant Physiology-Innovation Centre,

University of Turin, Via Quarello

15/A, I-10135 Turin, Italy

e-mail:massimo.maffei@unito.it
The geomagnetic field (GMF) is a natural component of our environment. Plants, which are known to sense different wavelengths of light, respond to gravity, react to touch and electrical signaling, cannot escape the effect of GMF. While phototropism, gravitropism, and tigmotropism have been thoroughly studied, the impact of GMF on plant growth and development is not well-understood. This review describes the effects of altering magnetic field (MF) conditions on plants by considering plant responses to MF values either lower or higher than those of the GMF. The possible role of GMF on plant evolution and the nature of the magnetoreceptor is also discussed.

Keywords: geomagnetic field, plant responses, evolution, magnetoreception, cryptochrome

\section{INTRODUCTION}

A magnetic field (MF) is an inescapable environmental factor for plants on the Earth. During the evolution process, all living organisms experienced the action of the Earth's MF (geomagnetic, GMF), which is a natural component of their environment. GMF is steadily acting on living systems, and is known to influence many biological processes. There are significant local differences in the strength and direction of the earth's magnetic (geomagnetic) field. At the surface of the earth, the vertical component is maximal at the magnetic pole, amounting to about $67 \mu \mathrm{T}$ and is zero at the magnetic equator. The horizontal component is maximal at the magnetic equator, about $33 \mu \mathrm{T}$, and is zero at the magnetic poles (Kobayashi et al., 2004). A MF is usually measured in terms of its magnetic induction $\mathbf{B}$ whose unit is given in Tesla (T), defined as:

$$
T=\frac{V \bullet s}{m^{2}}=\frac{W b}{m^{2}}=\frac{N \bullet s}{c \bullet m}
$$

The dimension of the "magnetic flux" $(\varphi)$ in SI units is Weber $(\mathrm{Wb})\left(\varphi=T m^{2}=W b\right)$.

The MF strength at the Earth's surface ranges from less than $30 \mu \mathrm{T}$ in an area including most of South America and South Africa (the so called south Atlantic anomaly) to almost $70 \mu \mathrm{T}$ around the magnetic poles in northern Canada and south of Australia, and in part of Siberia (Occhipinti et al., 2014). Most of the MF observed at the Earth's surface has an internal origin. It is mainly produced by the dynamo action of turbulent flows in the fluid metallic outer core of the planet, while little is due to external MFs located in the ionosphere and the magnetosphere (Qamili et al., 2013). It is the presence of the GMF that, through the magnetosphere, protects the Earth, together with its biosphere, from the solar wind deflecting most of its charged particles (Occhipinti et al., 2014).
The literature describing the effects of weak MFs on living systems contains a plethora of contradictory reports, few successful independent replication studies and a dearth of plausible biophysical interaction mechanisms. Most such investigations have been unsystematic, devoid of testable theoretical predictions and, ultimately, unconvincing (Harris et al., 2009). The progress and status of research on the effect of MF on plant life have been reviewed in the past years (Phirke et al., 1996; Abe et al., 1997; Volpe, 2003; Belyavskaya, 2004; Bittl and Weber, 2005; Galland and Pazur, 2005; Minorsky, 2007; Vanderstraeten and Burda, 2012; Occhipinti et al., 2014).

Krylov and Tarakonova (1960) were among the first to report on MF effects on plants. They proposed an auxin-like effect of the MF on germinating seeds, by calling this effect magnetotropism. The auxin-like effect of MF was also suggested to explain ripening of tomato fruits (Boe and Salunkhe, 1963). There was evidence that the root-growth response was not directly heliotropic but rather magnetotropic or geo-magnetotropic. Observation of the roots of a number of other plants suggested that some inherent factor within a species or even within a variety of a species could also be necessary before the tropism became manifest (Pittman, 1962). Because of the insufficient understanding of the biological action of MFs and its mechanism, it is rare to document the magnetic environment as a controlled factor for scientific experiment. Anyway, from these pioneering studies on, we can consider two experimental approaches aimed to evaluate the physiological responses of plant exposed to either weak or strong MFs.

\section{EXPOSURE OF PLANTS TO A MF INTENSITY LOWER THAN THE GEOMAGNETIC FIELD}

The term weak or low MF is generally referred to the intensities from $100 \mathrm{nT}$ to $0.5 \mathrm{mT}$, whereas superweak or conditionally zero (the so called magnetic vacuum) is related to MFs below 
$100 \mathrm{nT}$. Investigations of low MF effects on biological systems have attracted attention of biologists for several reasons. For instance, interplanetary navigation will introduce man, animals and plants in magnetic environments where the MF is near $1 \mathrm{nT}$. It is known that a galactic MF induction does not exceed $0.1 \mathrm{nT}$, in the vicinity of the Sun $(0.21 \mathrm{nT})$, and on the Venus surface (3 nT) (Belov and Bochkarev, 1983). This brought a new wave of interest in MF role in regulating plant growth and development (Belyavskaya, 2004). In laboratory, low MF have been created by different methods, including shielding (surrounding the experimental zone by ferromagnetic metal plates with high magnetic permeability, which deviate MF and concentrate it in the metal) and compensating (by using Helmholtz coils). In general, developmental studies on plant responses have been performed at various MF intensities. Early in 1963, it was found that a MF of relatively low intensity could be effective in stimulating or initiating plant growth responses (Pittman, 1963). Since then, a few experiments evaluated the effects of reduced MF conditions if compared to those performed by using high intensity MFs.

\section{EFFECTS ON PLANT DEVELOPMENT}

Sunflower (Helianthus annuus) seedlings exposed to $20 \mu \mathrm{T}$ vertical MF showed small, but significant increases in total fresh weights, shoot fresh weights, and root fresh weights, whereas dry weights and germination rates remained unaffected (Fischer et al., 2004).

Pea (Pisum sativum) epicotyls were longer in low MF (11.2 \pm $4.2 \mathrm{~mm}, n=14$ ) when compared to normal geomagnetic conditions ( $8.8 \pm 4.0 \mathrm{~mm}, n=12$ ) (Yamashita et al., 2004). Elongation of pea epicotyl was confirmed, by microscopic observation of sectioned specimen, to result from the elongation of cells and osmotic pressure of seedlings was significantly higher in low MF than controls. This observation suggests that the promotion of cell elongation under low MF may relate to an increase of osmotic pressure in the cells (Negishi et al., 1999). Furthermore, pea seedlings showed ultrastructural peculiarities such as a noticeable accumulation of lipid bodies, development of a lytic compartment (vacuoles, cytosegresomes, and paramural bodies), and reduction of phytoferritin in plastids. Mitochondria were the most sensitive organelle to low MF treatment and their size and relative volume in cells increased, matrix was electrontransparent, and cristae reduced. It was also observed that low MF effects on ultrastructure of root cells were due to disruptions in different metabolic systems including effects on $\mathrm{Ca}^{2+}$ homeostasis (Belyavskaya, 2001).

In broad bean (Vicia faba) seedlings, low MF intensities of 10 and $100 \mu \mathrm{T}$ at 50 or $60 \mathrm{~Hz}$ were observed to alter membrane transport processes in root tips (Stange et al., 2002), whereas seeds of soybean (Glycine max) exposed to pulsed MF of $1500 \mathrm{nT}$ at $0.1,1.0,10.0$, and $100.0 \mathrm{~Hz}$ for $5 \mathrm{~h}$ per day for 20 days, induced by enclosure coil systems, significantly increased the rate of seed germination, while 10 and $100 \mathrm{~Hz}$ pulsed MFs showed the most effective response (Radhakrishnan and Kumari, 2013). Treatment with MF also improved germination-related parameters like water uptake, speed of germination, seedling length, fresh weight, dry weight, and vigor indices of soybean seeds under laboratory conditions (Shine et al., 2011).
Controversial data have also been reported. The exposure to near null MF of different in vitro cultures of various species of the genus Solanum was either stimulating or inhibiting the growth of in vitro plants. The effect was apparently also dependent on the species, genotype, type of initial explant, treatment duration, or even culture medium (Rakosy-Tican et al., 2005).

By using ferromagnetic shields, the influence of weak, alternating MF, which was adjusted to the cyclotron frequency of $\mathrm{Ca}^{2+}$ and $\mathrm{K}^{+}$ions, was studied on the fusion of tobacco (Nicotiana tabacum) and soybean protoplasts. It was observed that in these conditions protoplasts fusion increased its frequency 2-3 times with the participation of calcium ions in the induction of protoplast fusion (Nedukha et al., 2007). The observations of the increase in the $\left[\mathrm{Ca}^{2+}\right]_{\text {cyt }}$ level after exposure to very low MF suggests that $\mathrm{Ca}^{2+}$ entry into the cytosol might constitute an early MF sensing mechanism (Belyavskaya, 2001).

When wheat (Triticum aestivum) seeds were treated with lowfrequency magnetic MF at the stage of esterase activation during seed swelling, the activation of esterases was enhanced by changing qualitatively the time course of the release of reaction products into the medium. These results helped to explain unusual dependences of biological effects on the amplitude of the electromagnetic field (EMF), including the atypical enhancement of these effects by the action of weak low-frequency fields (Aksenov et al., 2000). A two-layer permalloy magnetic screen was used to test the effects of a wide range of low MF (from $20 \mathrm{nT}$ to $0.1 \mathrm{mT}$ ) on 3-5 day old wheat seedlings. It was observed that seedlings grew slower than controls (Bogatina et al., 1978).

Barley (Hordeum vulgare) seedlings grown in Helmholtz coils with a $10 \mathrm{nT}$ MF intensity showed a decrease in fresh weight of shoots (by 12\%) and roots (by 35\%), as well as dry weight of shoots (by 19\%) and roots (by 48\%) in comparison with GMF controls. From this pioneer study it was concluded that very low MF was capable of delaying both organ formation and development (Lebedev et al., 1977).

The effect of a combined MF at the resonance frequency of $\mathrm{Ca}^{2+}$ ions inside a $\mu$-metal shield and the altered gravitropic reaction of cress (Lepidium sativum) roots was performed to evaluate the structure and functional organization of root cap statocytes. The experimented conditions were observed to change normally positively gravitropic cress root to exhibit negative gravitropism (Kordyum et al., 2005).

Artificial shielding of GMF caused a significant decrease in the cell number with enhanced DNA content in root and shoot of onion (Allium cepa) meristems. Furthermore, the uncytokinetic mitosis with formation of binuclear and then tetranuclear cells as well as a fusion of normal nuclei resulting in appearance of giant cells with vast nuclei seems to dominate in very low MF conditions (Nanushyan and Murashov, 2001).

Changes in the ultrastructural organization of some organelles and cellular compartments, alterations in condensed chromatin distribution and reduction in volume of granular nucleolus component with the appearance of nucleolus vacuoles were also found in several other species exposed to very low MF, indicating a decrease in activities of rRNA synthesis in some nucleoli (Belyavskaya, 2004 and references cited therein). 


\section{EFFECTS ON TRANSITION TO FLOWERING}

Near-null MF can be produced by three mutually perpendicular couples of Helmholtz coils and three sources of high-precision direct current power, which can counteract the vertical, northsouth and east-west direction components of the geomagnetic field (GMF) (Xu et al., 2012).

Although the functions of cryptochrome have been welldemonstrated for Arabidopsis thaliana, the effect of the GMF on the growth of Arabidopsis and its mechanism of action are poorly understood. In Arabidopsis seedlings grown in a near-null MF flowering was delayed by ca. 5 days compared with those grown in the GNF. Moreover, PCR analyses of three cryptochromesignaling-related genes, $P H Y B, C O$, and FT also changed; the transcript level of $P H Y B$ was elevated ca. $40 \%$, and that of $C O$ and FT was reduced ca. 40 and 50\%, respectively. These data suggest that the effects of a near-null MF on Arabidopsis might be cryptochrome-related, which may be revealed by a modification of the active state of cryptochrome and the subsequent signaling cascade (Xu et al., 2012). Moreover, the biomass accumulation of plants in the near-null MF was significantly suppressed at the time when plants were switching from vegetative growth to reproductive growth compared with that of plants grown in the local GMF, which was caused by the delay in the flowering of plants in the near-null MF. These resulted in a significant reduction of about $20 \%$ in the harvest index of plants in the near-null MF compared with that of the controls. Therefore, the removal of the local GMF negatively affects the reproductive growth of Arabidopsis, which thus affects the yield and harvest index (Xu et al., 2013).

\section{EXPOSURE OF PLANTS TO MF INTENSITIES HIGHER THAN THE GEOMAGNETIC FILED}

A consistent number of papers described the effect of MF intensities higher than the GMF levels. In general, intensities higher than GMF relate to values higher than $100 \mu \mathrm{T}$. As summarized in Table 1, experimental values can reach very high MF levels, ranging from $500 \mu \mathrm{T}$ up to $15 \mathrm{~T}$. Most of the attention has been focused on seed germination of important crops like wheat, rice and legumes. However, many other physiological effects on plants of high MF described plant responses in terms of growth, development, photosynthesis, and redox status.

\section{EFFECTS ON GERMINATION}

A MF applied to dormant seeds was found to increase the rate of subsequent seedling growth of barley, corn (Zea mays), beans, wheat, certain tree fruits, and other tree species. Moreover, a low frequency $\mathrm{MF}(16 \mathrm{~Hz})$ can be used as a method of post-harvest seed improvement for different plant species, especially for seeds of temperature sensitive species germinating at low temperatures (Rochalska and Orzeszko-Rywka, 2005).

Seeds of hornwort (Cryptotaenia japonica) exposed to sinusoidally time-varying extremely low frequency (ELF) MFs (AC fields) in combination with the local GMF showed a promoted activity of cells and enzymes in germination stage of the seed. This suggests that an optimum ELF MF might exist for the germination of hornwort seeds under the local GMF (Kobayashi et al., 2004). The application of AC field also promoted the germination of bean (Phaseolus vulgaris) seeds (Sakhnini, 2007).
In seeds of mung bean (Vigna radiata), exposed in batches to static MFs of 87 to $226 \mathrm{mT}$ intensity for $100 \mathrm{~min}$, a linear increase in germination magnetic constant with increasing intensity of MF was found. Calculated values of mean germination time, mean germination rate, germination rate coefficient, germination magnetic constant, transition time, water uptake, indicate that the impact of applied static MF improves the germination of mung beans seeds even in off-season (Mahajan and Pandey, 2014).

The seeds of pea exposed to full-wave rectified sumusoidal non-uniform MF of strength 60,120, and $180 \mathrm{mT}$ for 5, 10, and 15 min prior to sowing showed significant increase in germination. The emergence index, final emergence index and vigor index increased by 86,13 , and $205 \%$, respectively. Furthermore, it was found that exposure of $5 \mathrm{~min}$ for MF strengths of 60 and $180 \mathrm{mT}$ significantly enhanced the germination parameters of the pea and these treatments could be used practically to accelerate the germination in pea (Iqbal et al., 2012).

MF application with a strength from 0 to $250 \mathrm{mT}$ in steps of $50 \mathrm{mT}$ for $1-4 \mathrm{~h}$ significantly enhanced speed of germination, seedling length and seedling dry weight compared to unexposed control in chickpea (Cicer arietinum). It was also found that magnetically treated chickpea seeds may perform better under rainfed (un-irrigated) conditions where there was a restrictive soil moisture regime (Vashisth and Nagarajan, 2008).

Different intensities of static MF ( 4 or $7 \mathrm{mT}$ ) were tested on seed germination and seedling growth of bean or wheat seeds in different media having 0, 2, 6, and 10 atmosphere (atm) osmotic pressure prepared with sucrose or salt. The application of both MFs promoted the germination ratios, regardless of increasing osmotic pressure of sucrose or salt. The greatest germination and growth rates in both plants were from the test groups exposed to $7 \mathrm{mT}$ (Cakmak et al., 2010).

Seeds of wheat were imbibed in water overnight and then treated with or without a $30 \mathrm{mT}$ static magnetic field (SMF) and a $10 \mathrm{kHz}$ EMF for 4 days, each $5 \mathrm{~h}$. Exposure to both MF increased the speed of germination, compared to the control group, suggesting promotional effects of EMFs on membrane integrity and growth characteristics of wheat seedlings (Payez et al., 2013).

Pre-sowing treatment of corn seeds with pulsed EMFs for $0,15,30$, and $45 \mathrm{~min}$ improved germination percentage, vigor, chlorophyll content, leaf area, plant fresh and dry weight, and finally yields. Seeds that have been exposed to MF for 30 and $45 \mathrm{~min}$ have been found to perform the best results with economic impact on producer's income in a context of a modern, organic, and sustainable agriculture (Bilalis et al., 2012).

Various combinations of MF strength and exposure time significantly improved tomato (Solanum lycopersicum) cv. Lignon seed performance in terms of reduction of time required for the first seeds to complete germination, time to reach $50 \%$ germination, time between 10 and $90 \%$ germination with increasing germination rate, and increased germination percentage at 4 and 7 days, seedling shoot and root length compared to the untreated control seeds. The combinations of $160 \mathrm{mT}$ for $1 \mathrm{~min}$ and $200 \mathrm{mT}$ for $1 \mathrm{~min}$ gave the best results (De Souza et al., 2010). Higher germination (about 11\%) was observed in magnetically-exposed tomato var. MST/32 seed than in non-exposed ones, suggesting a 
Table 1 | Summary of magnetic field (MF) effects on plants.

\begin{tabular}{|c|c|c|c|c|}
\hline Plant species & Plant organ & Effect & $\begin{array}{l}\text { MF } \\
\text { intensity }\end{array}$ & References \\
\hline \multicolumn{5}{|c|}{ EXPOSURE TO MF VALUES LOWER THAN THOSE OF THE GMF } \\
\hline Allium сера & Root and shoot & $\begin{array}{l}\text { Decrease in the cell number with enhanced } \\
\text { DNA content }\end{array}$ & $<\mathrm{GMF}$ & $\begin{array}{l}\text { Nanushyan and Murashov, 2001; } \\
\text { Belyavskaya, } 2004 \text { and references } \\
\text { cited therein }\end{array}$ \\
\hline Arabidopsis thaliana & & $\begin{array}{l}\text { Delayed flowering } \\
\text { Reproductive growth }\end{array}$ & Near null & Xu et al., 2012, 2013 \\
\hline Glycine max & $\begin{array}{l}\text { Protoplasts } \\
\text { Seeds }\end{array}$ & $\begin{array}{l}\text { Increased protoplasts fusion } \\
\text { Seed germination }\end{array}$ & $\begin{array}{l}<\mathrm{GMF} \\
1500 \mathrm{nT}\end{array}$ & $\begin{array}{l}\text { Nedukha et al., } 2007 \\
\text { Radhakrishnan and Kumari, } 2013\end{array}$ \\
\hline Lepidium sativum & Roots & Negative gravitropism & $<\mathrm{GMF}$ & Kordyum et al., 2005 \\
\hline Nicotiana tabacum & Protoplasts & Increased protoplasts fusion & $<\mathrm{GMF}$ & Nedukha et al., 2007 \\
\hline Pisum sativum & Epicotyl & $\begin{array}{l}\text { Promotion of cell elongation; ultrastructural } \\
\text { peculiarities increase in the }\left[\mathrm{Ca}^{2+}\right]_{\text {cyt }} \text { level }\end{array}$ & $<\mathrm{GMF}$ & $\begin{array}{l}\text { Negishi et al., 1999; Belyavskaya, } \\
\text { 2001; Yamashita et al., } 2004\end{array}$ \\
\hline Solanum spp. & $\begin{array}{l}\text { In vitro } \\
\text { cultures }\end{array}$ & Stimulation/inhibition of growth & $<\mathrm{GMF}$ & Rakosy-Tican et al., 2005 \\
\hline Triticum aestivum & $\begin{array}{l}\text { Seeds and } \\
\text { seedlings }\end{array}$ & $\begin{array}{l}\text { Activation of esterases } \\
\text { reduction of growth }\end{array}$ & $\begin{array}{l}\text { from } 20 \mathrm{nT} \\
\text { to } 0.1 \mathrm{mT}\end{array}$ & $\begin{array}{l}\text { Bogatina et al., 1978; Aksenov et al., } \\
2000\end{array}$ \\
\hline Arabidopsis thaliana & $\begin{array}{l}\text { Seedlings } \\
\text { Callus culture }\end{array}$ & $\begin{array}{l}\text { Enhanced blue light-dependent } \\
\text { phosphorylations of CRY1 and CRY2; hypocotyl } \\
\text { growth } \\
\text { Amyloplast displacement } \\
\text { Diamagnetic levitation } \\
\text { Proteomic alterations } \\
\text { Induced expression of the Adh/GUS transgene } \\
\text { in the roots and leaves }\end{array}$ & $\begin{array}{l}500 \mu T \\
15 T\end{array}$ & $\begin{array}{l}\text { Harris et al., 2009; Xu et al., } 2014 \\
\text { Weise et al., } 2000 \\
\text { Manzano et al., } 2013 \\
\text { Herranz et al., } 2013 \\
\text { Paul et al., } 2006\end{array}$ \\
\hline Beta vulgaris & Seedlings & $\begin{array}{l}\text { Increased root and leaf yield } \\
\text { Increased chlorophyll content }\end{array}$ & $5 \mathrm{mT}$ & $\begin{array}{l}\text { Rochalska, } 2008 \\
\text { Rochalska, } 2005\end{array}$ \\
\hline Carica papaya & Pollen & Increased pollen germination & $>\mathrm{GMF}$ & Alexander and Ganeshan, 1990 \\
\hline Catharanthus roseus & Protoplast & Effect on cell wall & $302 \mathrm{mT}$ & Haneda et al., 2006 \\
\hline Cicer arietinum & $\begin{array}{l}\text { Seed } \\
\text { Root }\end{array}$ & $\begin{array}{l}\text { Promotion of germination } \\
\text { Increase in root length, surface area and volume }\end{array}$ & $0-250 \mathrm{mT}$ & Vashisth and Nagarajan, 2008 \\
\hline Coffea arabica & Seedlings & Decrease of SOD, CAT, and APX activities & $2 \mathrm{mT}$ & Aleman et al., 2014 \\
\hline
\end{tabular}


Table 1 | Continued

\begin{tabular}{|c|c|c|c|c|}
\hline Plant species & Plant organ & Effect & $\begin{array}{l}\text { MF } \\
\text { intensity }\end{array}$ & References \\
\hline $\begin{array}{l}\text { Cryptotaenia } \\
\text { japonica }\end{array}$ & Seed & Promotion of germination & $500,750 \mu \top$ & Kobayashi et al., 2004 \\
\hline Cucumis sativus & Seedlings & Increase in superoxide radicals and $\mathrm{H}_{2} \mathrm{O}_{2}$ & $100-250 \mathrm{mT}$ & Bhardwaj et al., 2012 \\
\hline Desmodium gyrans & Leaf & Reduced rhythmic leaflet movements & $50 \mathrm{mT}$ & Sharma et al., 2000 \\
\hline Dioscorea opposita & Seedling & Increased root length and number & $2 \times \mathrm{GMF}$ & Li, 2000 \\
\hline Fragaria vesca & Plantlets & Increased fruit yield per plant & $\begin{array}{l}0.096,0.192 \\
\text { and } 0.384 \mathrm{~T}\end{array}$ & Esitken and Turan, 2004 \\
\hline Glycine max & Seedlings & $\begin{array}{l}\text { Reduction of } \mathrm{O}_{2} \text {-radical level } \\
\text { Reactive oxygen species production } \\
\text { Increased Rubisco }\end{array}$ & $150,200 \mathrm{mT}$ & $\begin{array}{l}\text { Baby et al., 2011; Radhakrishnan and } \\
\text { Kumari, 2012, 2013; Shine et al., } 2012 \\
\text { Shine et al., } 2011\end{array}$ \\
\hline Helianthus annuus & Seedlings & $\begin{array}{l}\text { Increased seedling dry weight, root length, root } \\
\text { surface area and root volume } \\
\text { Increased activities of } \alpha \text {-amylase, } \\
\text { dehydrogenase and protease }\end{array}$ & $50,200 \mathrm{mT}$ & Vashisth and Nagarajan, 2010 \\
\hline Helianthus annuus & Seedlings & Increased chlorophyll concentration & $>\mathrm{GMF}$ & Turker et al., 2007 \\
\hline Helix aspesa & Seedlings & Oxidative burst & $50-\mathrm{Hz}$ & Regoli et al., 2005 \\
\hline Hordeum vulgare & Seedlings & Increases in length and weight & $125 \mathrm{mT}$ & Martinez et al., 2000 \\
\hline Leymus chinensis & Seedlings & Increased peroxidase activity & $200,300 \mathrm{mT}$ & Xia and Guo, 2000 \\
\hline Oryza sativa & Seed & Reduction of germination & $125,250 \mathrm{mT}$ & Florez et al., 2004 \\
\hline Paulownia fortunei & Tissue cultures & Increased regeneration capability & $2.9-4.8 \mathrm{mT}$ & Yaycili and Alikamanoglu, 2005 \\
\hline $\begin{array}{l}\text { Paulownia } \\
\text { tomentosa }\end{array}$ & Tissue cultures & Increased regeneration capability & $2.9-4.8 \mathrm{mT}$ & Yaycili and Alikamanoglu, 2005 \\
\hline $\begin{array}{l}\text { Petroselinum } \\
\text { crispum }\end{array}$ & Cells & Effects on CAT and APX activity & $30 \mathrm{mT}$ & Rajabbeigi et al., 2013 \\
\hline Phaseolus vulgaris & Seeds & $\begin{array}{l}\text { Promotion of germination } \\
\text { Increased chlorophyll emission fluorescence }\end{array}$ & $\begin{array}{l}2 \text { or } 7 \mathrm{mT} \\
3100,160 \mathrm{mT}\end{array}$ & $\begin{array}{l}\text { Sakhnini, 2007; Cakmak et al., } 2010 \\
\text { Jovanic and Sarvan, } 2004\end{array}$ \\
\hline Pisum sativum & $\begin{array}{l}\text { Seed } \\
\text { Seedlings }\end{array}$ & $\begin{array}{l}\text { Promotion of germination } \\
\text { Increased length and weight } \\
\text { Induction of SOD activity }\end{array}$ & $\begin{array}{l}60,120,180 \mathrm{mT} \\
125,250 \mathrm{mT}\end{array}$ & $\begin{array}{l}\text { lqbal et al., } 2012 \\
\text { Carbonell et al., } 2011 \\
\text { Polovinkina et al., } 2011\end{array}$ \\
\hline Raphanus sativus & Seedlings & $\begin{array}{l}\text { Suppression of SOD and CAT activities } \\
\text { Reduced } \mathrm{CO}_{2} \text { uptake } \\
\text { Stimulation of lipid synthesis }\end{array}$ & $\begin{array}{l}185-650 \mu T \\
500 \mu T\end{array}$ & $\begin{array}{l}\text { Serdyukov and Novitskii, } 2013 \\
\text { Yano et al., } 2004 \\
\text { Novitskaya et al., 2010; Novitskii et al., } \\
2014\end{array}$ \\
\hline $\begin{array}{l}\text { Solanum } \\
\text { lycopersicum }\end{array}$ & $\begin{array}{l}\text { Seed } \\
\text { Shoots }\end{array}$ & $\begin{array}{l}\text { Promotion of germination } \\
\text { Effect on gravitropismo } \\
\text { Magnetophoretic curvature } \\
\text { Increased mean fruit weight, yield per plant and } \\
\text { per area } \\
\text { Geminivirus and early blight and a reduced } \\
\text { infection rate }\end{array}$ & $160-200 \mathrm{mT}$ & $\begin{array}{l}\text { De Souza et al., 2010; Poinapen et al., } \\
\text { 2013a } \\
\text { Hasenstein and Kuznetsov, } 1999 \\
\text { De Souza et al., } 2006\end{array}$ \\
\hline
\end{tabular}


Table 1 | Continued

\begin{tabular}{|c|c|c|c|c|}
\hline Plant species & Plant organ & Effect & $\begin{array}{l}\text { MF } \\
\text { intensity }\end{array}$ & References \\
\hline Solanum tuberosum & $\begin{array}{l}\text { Seedlings } \\
\text { Plantlets }\end{array}$ & $\begin{array}{l}\text { Amyloplast displacement } \\
\text { Growth promotion and enhancement of } \\
\mathrm{CO}_{2} \text { uptake } \\
\text { enhanced lipid order }\end{array}$ & $4 \mathrm{mT}$ & $\begin{array}{l}\text { Hasenstein et al., } 2013 \\
\text { limoto et al., } 1998 \\
\text { Poinapen et al., } 2013 \mathrm{~b}\end{array}$ \\
\hline Taxus chinensis & $\begin{array}{l}\text { Suspension } \\
\text { culture }\end{array}$ & Promotion of taxol production & $3.5 \mathrm{mT}$ & Shang et al., 2004 \\
\hline Tradescantia spp. & Inflorescence & Pink mutations in stamen hair cells & $\begin{array}{l}0.16,0.76 \\
0.78 \mathrm{~T}\end{array}$ & Baum and Nauman, 1984 \\
\hline Triticum aestivum & $\begin{array}{l}\text { Seed } \\
\text { Seedlings }\end{array}$ & $\begin{array}{l}\text { Promotion of germination } \\
\text { Amyloplast displacement } \\
\text { increased catalase but reduced peroxidase } \\
\text { activity }\end{array}$ & $\begin{array}{l}4 \text { or } 7 \mathrm{mT} \\
30-\mathrm{mT} \\
30-\mathrm{mT}\end{array}$ & $\begin{array}{l}\text { Cakmak et al., } 2010 \\
\text { Hasenstein et al., } 2013 \\
\text { Payez et al., } 2013\end{array}$ \\
\hline Vicia faba & Plantlets & $\begin{array}{l}\text { Accumulation of ROS } \\
\text { Modification of catalase and MAPK; } \\
\text { accumulation of } \mathrm{H}_{2} \mathrm{O}_{2}\end{array}$ & $\begin{array}{l}15 \mathrm{mT} \\
30 \mathrm{mT}\end{array}$ & $\begin{array}{l}\text { Jouni et al., } 2012 \\
\text { Haghighat et al., } 2014\end{array}$ \\
\hline Vigna radiata & $\begin{array}{l}\text { Seed } \\
\text { Seedlings }\end{array}$ & $\begin{array}{l}\text { Promotion of germination } \\
\text { Decrease of malondialdehyde, } \mathrm{H}_{2} \mathrm{O}_{2} \text { and } \mathrm{O}_{2}^{-} \text {, } \\
\text { and increase of } \mathrm{NO} \text { and NOS activity }\end{array}$ & $\begin{array}{l}87 \text { to } 226 \mathrm{mT} \\
600 \mathrm{mT}\end{array}$ & $\begin{array}{l}\text { Mahajan and Pandey, } 2014 \\
\text { Chen et al., } 2011\end{array}$ \\
\hline Zea mays & $\begin{array}{l}\text { Seed } \\
\text { Seedlings }\end{array}$ & $\begin{array}{l}\text { Promotion of germination } \\
\text { Increase of fresh weight } \\
\text { Amyloplast displacement } \\
\text { Decreased levels of hydrogen peroxide and } \\
\text { antioxidant defense system enzymes } \\
\text { Reduction of antioxidant enzymes } \\
\text { Increased stomatal conductance and chlorophyll } \\
\text { content }\end{array}$ & $\begin{array}{l}125,250 \mathrm{mT} \\
100,200 \mathrm{mT}\end{array}$ & $\begin{array}{l}\text { Bilalis et al., } 2012 \\
\text { Florez et al., } 2007 \\
\text { Hasenstein et al., } 2013 \\
\text { Anand et al., } 2012 \\
\text { Shine and Guruprasad, } 2012 \\
\text { Turker et al., 2007; Javed et al., 2011; } \\
\text { Anand et al., } 2012\end{array}$ \\
\hline
\end{tabular}

significant effect of non-uniform MFs on seed performance with respect to RH (Poinapen et al., 2013a).

The effect of pre-sowing magnetic treatments was investigated on germination, growth, and yield of okra (Abelmoschus esculentus cv. Sapz paid) with an average MF exposure of $99 \mathrm{mT}$ for 3 and $11 \mathrm{~min}$. A significant increase $(P<0.05)$ was observed in germination percentage, number of flowers per plant, leaf area, plant height at maturity, number of fruits per plant, pod mass per plant, and number of seeds per plant. The $99 \mathrm{mT}$ for $11 \mathrm{~min}$ exposure showed better results as compared to control (Naz et al., 2012).

However, contrasting results have also been reported. For instance, the mean germination time of rice (Oryza sativa) seeds exposed to one of two MF strengths ( 125 or $250 \mathrm{mT}$ ) for different times ( $1 \mathrm{~min}, 10 \mathrm{~min}, 20 \mathrm{~min}, 1 \mathrm{~h}, 24 \mathrm{~h}$, or chronic exposure) was significantly reduced compared to controls, indicating that this type of magnetic treatment clearly affects germination and the first stages of growth of rice plants (Florez et al., 2004).

\section{EFFECTS ON CRYPTOCHROME}

The blue light receptor cryptochrome can form radical pairs after exposure to blue light and has been suggested to be a potential magnetoreceptor based on the proposition that radical pairs are involved in magnetoreception. Nevertheless, the effects of MF on the function of cryptochrome are poorly understood. When Arabidopsis seedlings were grown in a $500 \mu \mathrm{T}$ MF and a nearnull MF it was found that the $500 \mu \mathrm{T}$ MF enhanced the blue light-dependent phosphorylations of CRY1 and CRY2, whereas the near-null MF weakened the blue light-dependent phosphorylation of CRY2 but not CRY1. Dephosphorylations of CRY1 and CRY2 in the darkness were slowed down in the $500 \mu \mathrm{T} \mathrm{MF}$, whereas dephosphorylations of CRY1 and CRY2 were accelerated in the near-null MF. These results suggest that MF with strength higher or weaker than the local GMF affects the activated states of cryptochromes, which thus modifies the functions of cryptochromes (Xu et al., 2014). Moreover, the magnitude of the hyperfine coupling constants $\left(\mathrm{A}_{\max }^{(\mathrm{iso})}=17.5 \mathrm{G}\right)$ suggests that artificial MFs ( $1-5 \mathrm{G})$ involved in experiments with Arabidopsis can affect the signal transduction rate. On the other hand, hyperfine interactions in the $\mathrm{FADH}^{*}-\mathrm{Trp}^{*+}$ biradicals are much stronger than the Zeeman interaction with the MF of the Earth $(\approx 0.5 \mathrm{G})$. Therefore, an alternative mechanism for the bird avian compass has been proposed very recently. This mechanism involves radicals with weaker hyperfine interactions $\left(\mathrm{O}_{2}^{--}\right.$and $\left.\mathrm{FADH} \cdot{ }^{-}\right)$, and thus, it could be more plausible for explaining incredible 
sensitivity of some living species to even tiny changes in the MF (Izmaylov et al., 2009).

However, contrasting results were obtained when the intensity of the ambient MF was varied from $33-44$ to $500 \mu \mathrm{T}$. According to Ahmad et al. (2007) there was an enhanced growth inhibition in Arabidopsis under blue light, when cryptochromes are the mediating photoreceptor, but not under red light when the mediating receptors are phytochromes, or in total darkness. Hypocotyl growth of Arabidopsis mutants lacking cryptochromes was unaffected by the increase in magnetic intensity. Additional cryptochrome-dependent responses, such as blue-light-dependent anthocyanin accumulation and blue-lightdependent degradation of CRY2 protein, were also enhanced at the higher magnetic intensity. On the contrary, Harris et al. (2009) by using the experimental conditions chosen to match those of the Ahmad study, found that in no case consistent, statistically significant MF responses were detected. For a more comprehensive discussion on cryptochromes see below.

\section{EFFECTS ON ROOTS AND SHOOTS}

Increased growth rates have been observed in different species when seeds where treated with increased MF. Treated corn plants grew higher and heavier than control, corresponding with increase of the total fresh weight. The greatest increases were obtained for plants continuously exposed to 125 or $250 \mathrm{mT}$ (Florez et al., 2007). A stimulating effect on the first stages of growth of barley seeds was found for all exposure times studied. When germinating barley seeds were subjected to a MF of $125 \mathrm{mT}$ for different times $(1,10,20$, and $60 \mathrm{~min}, 24 \mathrm{~h}$, and chronic exposure), increases in length and weight were observed (Martinez et al., 2000). Pants of pea exposed to 125 or $250 \mathrm{mT}$ stationary MF generated by magnets under laboratory conditions for 1,10 , and $20 \mathrm{~min}, 1$ and $24 \mathrm{~h}$ and continuous exposure were longer and heavier than the corresponding controls at each time of evaluation. The major increases occurred when seeds were continuously exposed to the MF (Carbonell et al., 2011).

By treating with twice gradient MF Dioscorea opposita it was found that they could grow best in the seedling stage. Compared with the control, the rate of emergence increased by $39 \%$, root number increased by $8 \%$, and the average root length increased by $2.62 \mathrm{~cm}(\mathrm{Li}, 2000)$. The $16 \mathrm{~Hz}$ frequency and $5 \mathrm{mT} \mathrm{MF}$ as well as alternating MF influence increased sugar beet (Beta vulgaris var saccharifera) root and leaf yield (Rochalska, 2008); while a dramatic increase in root length, root surface area and root volume was observed in chickpea exposed in batches to static MF of strength from 0 to $250 \mathrm{mT}$ in steps of $50 \mathrm{mT}$ for $1-4 \mathrm{~h}$ (Vashisth and Nagarajan, 2008). In the same conditions, seedlings of sunflower showed higher seedling dry weight, root length, root surface area and root volume. Moreover, in germinating seeds, enzyme activities of $\alpha$-amylase, dehydrogenase and protease were significantly higher in treated seeds than controls (Vashisth and Nagarajan, 2010).

\section{EFFECTS ON GRAVITROPIC RESPONSES}

The growth response that is required to maintain the spatial orientation is called gravitropism and consists of three phases: reception of a gravitational signal, its transduction to a biochemical signal that is transported to the responsive cells and finally the growth response, or bending of root, or shoot. Primary roots exhibit positive gravitropism, i.e., they grow in the direction of a gravitational vector. Shoots respond negatively to gravity and grow upright opposite to the gravitational vector. However, lateral roots and shoots branches are characterized by intermediate setpoint angles and grow at a particular angle that can change over time (Firn and Digby, 1997). Gravitropism typically is generated by dense particles that respond to gravity. Experimental stimulation by high-gradient MF provide a new approach to selectively manipulate the gravisensing system.

High-gradient MF has been used to induce intracellular magnetophoresis of amyloplasts and the obtained data indicate that a magnetic force can be used to study the gravisensing and response system of roots (Kuznetsov and Hasenstein, 1996). The data reported strongly support the amyloplast-based gravitysensing system in higher plants and the usefulness of high MF to substitute gravity in shoots (Kuznetsov and Hasenstein, 1997; Kuznetsov et al., 1999). For example, in shoots of the lazy2 mutant of tomato that exhibit negative gravitropism in the dark, but respond positively gravitropically in (red) light, induced magnetophoretic curvature showed that lazy-2 mutants perceive the displacement of amyloplasts in a similar manner than wt and that the high MF does not affect the graviresponse mechanism (Hasenstein and Kuznetsov, 1999). Arabidopsis stems positioned in a high MF on a rotating clinostat demonstrate that the lack of apical curvature after basal amyloplast displacement indicates that gravity perception in the base is not transmitted to the apex (Weise et al., 2000). The movement of corn, wheat, and potato (Solanum tuberosum) starch grains in suspension was examined with videomicroscopy during parabolic flights that generated $20-25$ s of weightlessness. During weightlessness, a magnetic gradient was generated by inserting a wedge into a uniform, external MF that caused repulsion of starch grains. Magnetic gradients were able to move diamagnetic compounds under weightless or microgravity conditions and serve as directional stimulus during seed germination in low-gravity environments (Hasenstein et al., 2013). The response of transgenic seedlings of Arabidopsis, containing either the CycB1-GUS proliferation marker or the DR5-GUS auxin-mediated growth marker, to diamagnetic levitation in the bore of a superconducting solenoid magnet was evaluated. Diamagnetic levitation led to changes that are very similar to those caused by real- [e.g., on board the International Space Station (ISS)] or mechanically-simulated microgravity [e.g., using a Random Positioning Machine (RPM)]. These changes decoupled meristematic cell proliferation from ribosome biogenesis, and altered auxin polar transport (Manzano et al., 2013). Arabidopsis in vitro callus cultures were also exposed to environments with different levels of effective gravity and MF strengths simultaneously. The MF itself produced a low number of proteomic alterations, but the combination of gravitational alteration and MF exposure produced synergistic effects on the proteome of plants (Herranz et al., 2013). However, MF leads to redistribution of the cellular activities and this is why application of the proteomic analysis to the whole organs/plants is not so informative. 


\section{EFFECTS ON REDOX STATUS}

Effects of MFs have been related to uncoupling of free radical processes in membranes and enhanced ROS generation. It has been experimentally proven that MF can change activities of some scavenging enzymes such as catalase (CAT), superoxide dismutase (SOD), glutathione reductase (GR), glutathione transferase (GT), peroxidase (POD), ascobtate peroxidase (APX), and polyphenoloxidase (POP). Experiments have been performed on several plant species, including pea, land snail (Helix aspesa), radish (Raphanus sativus), Leymus chinensis, soybean, cucumber (Cucumis stivus), broad bean, corn, parsley (Petroselinum crispum), and wheat (Xia and Guo, 2000; Regoli et al., 2005; Baby et al., 2011; Polovinkina et al., 2011; Anand et al., 2012; Bhardwaj et al., 2012; Jouni et al., 2012; Radhakrishnan and Kumari, 2012, 2013; Shine and Guruprasad, 2012; Shine et al., 2012; Payez et al., 2013; Rajabbeigi et al., 2013; Serdyukov and Novitskii, 2013; Aleman et al., 2014; Haghighat et al., 2014). The results suggest that exposure to increased MF causes accumulation of reactive oxygen species and alteration of enzyme activities. The effects of continuous, low-intensity static MF $(7 \mathrm{mT})$ and $\mathrm{EF}(20 \mathrm{kV} / \mathrm{m})$ on antioxidant status of shallot (Allium ascalonicum) leaves, increased lipid peroxidation and $\mathrm{H}_{2} \mathrm{O}_{2}$ levels in EF applied leaves. These results suggested that apoplastic constituents may work as potentially important redox regulators sensing and signaling MF changes. Static continuous MF and $\mathrm{EF}$ at low intensities have distinct impacts on the antioxidant system in plant leaves, and weak MF is involved in antioxidantmediated reactions in the apoplast, resulting in overcoming a possible redox imbalance (Cakmak et al., 2012). In mung bean seedlings treated with $600 \mathrm{mT}$ MF followed by cadmium stress the concentration of malondialdehyde, $\mathrm{H}_{2} \mathrm{O}_{2}$ and $\mathrm{O}_{2}^{-}$, and the conductivity of electrolyte leakage decreased, while the NO concentration and NOS activity increased compared to cadmium stress alone, showing that MF compensates for the toxicological effects of cadmium exposure are related to NO signal (Chen et al., 2011).

\section{EFFECTS ON PHOTOSYNTHESIS}

Photosynthesis, stomatal conductance and chlorophyll content increased in corn plants exposed to static MFs of 100 and $200 \mathrm{mT}$, compared to control under irrigated and mild stress condition (Anand et al., 2012). Pre-seed electromagnetic treatments has been used to minimize the drought-induced adverse effects on different crop plants. Pretreatment of seeds of two corn cultivars with different magnetic treatments significantly alleviated the drought-induced adverse effects on growth by improving chlorophyll a and photochemical quenching and non-photochemical quenching. Of all magnetic treatments, 100 and $150 \mathrm{mT}$ for $10 \mathrm{~min}$ were most effective in alleviating the drought-induced adverse effects (Javed et al., 2011). Polyphasic chlorophyll $a$ fluorescence transients from magnetically treated soybean plants gave a higher fluorescence yield. The total soluble proteins of leaves showed increased intensities of the bands corresponding to a larger subunit $(53 \mathrm{KDa})$ and smaller subunit $(14 \mathrm{KDa})$ of Rubisco in the treated plants. Therefore, presowing magnetic treatment was found to improve biomass accumulation in soybean (Shine et al., 2011). Other general effects on MF application on chlorophyll content have been documented for several plant species (Voznyak et al., 1980; Rochalska, 2005; Turker et al., 2007; Radhakrishnan and Kumari, 2013).

The $\mathrm{CO}_{2}$ uptake rate of $\mathrm{MF}$ exposed radish seedlings was lower than that of the control seedlings. The dry weight and the cotyledon area of MF exposed seedlings were also significantly lower than those of the control seedlings (Yano et al., 2004). A MF of around $4 \mathrm{mT}$ had beneficial effects, regardless of the direction of MF, on the growth promotion and enhancement of $\mathrm{CO}_{2}$ uptake of potato plantlets in vitro. However, the direction of MF at the MF tested had no effects on the growth and $\mathrm{CO}_{2}$ exchange rate (Iimoto et al., 1998).

A permanent MF induces significant changes in bean leaf fluorescence spectra and temperature. The fluorescence intensity ratio (FIR) and change of leaf temperature $\Delta \mathrm{T}$ increase with the increase of MF intensity. The increase of $\Delta \mathrm{T}$ due to MFs is explained in bean with a simple ion velocity model. Reasonable agreement between calculated $\Delta \mathrm{T}$, based on the model, and measured $\Delta \mathrm{T}$ was obtained (Jovanic and Sarvan, 2004).

\section{EFFECTS ON LIPID COMPOSITION}

In radish seedlings grown in lowlight and darkness in an ELF MF characterized by $50 \mathrm{~Hz}$ frequency and approximate to $500 \mu \mathrm{T}$ flux density, MF exposure increased the production of polar lipids by threefold specifically, glycolipids content increased fourfold and phospholipids content rose 2.5 times, compared to seeds. MF stimulated lipid synthesis in chloroplast, mitochondrial, and other cell membranes (Novitskii et al., 2014). Furthermore, among fatty acids, MF exerted the strongest effect on the content of erucic acid: it increased in the light and in darkness approximately by $25 \%$ and decreased in the light by $13 \%$. Therefore, MF behaved as a correction factor affecting lipid metabolism on the background of light and temperature action (Novitskaya et al., 2010).

Plasma membranes of seeds of tomato plants were purified, extracted, and applied to a silicon substrate in a buffer suspension and their molecular structure was studied using X-ray diffraction. While MFs had no observable effect on protein structure, enhanced lipid order was observed, leading to an increase in the gel components and a decrease in the fluid component of the lipids (Poinapen et al., 2013b).

\section{OTHER EFFECTS}

Inflorescences from Tradescantia clones subjected to high MF showed pink mutations in stamen hair cells (Baum and Nauman, 1984). Pollen grains of papaya (Carica papaya) exposed to MF germinated faster and produced longer pollen tubes than the controls (Alexander and Ganeshan, 1990). In kiwifruit (Actinidia deliciosa) MF treatment partially removed the inhibitory effect caused by the lack of $\mathrm{Ca}^{2+}$ in the pollen culture medium, inducing a release of internal $\mathrm{Ca}^{2+}$ stored in the secretory vesicles of pollen plasma membrane (Betti et al., 2011). Short day strawberry (Fragaria vesca) plants treated with MF strengths of $0.096,0.192$, and 0.384 Tesla $(\mathrm{T})$ in heated greenhouse conditions showed increased fruit yield per plant (208.50 and $246.07 \mathrm{~g}$, respectively) and fruit number per plant (25.9 and 27.6, 
respectively), but higher MF strengths than $0.096 \mathrm{~T}$ reduced fruit yield and fruit number. Increasing MF strength from control to $0.384 \mathrm{~T}$ also increased contents of $\mathrm{N}, \mathrm{K}, \mathrm{Ca}, \mathrm{Mg}, \mathrm{Cu}$, $\mathrm{Fe}, \mathrm{Mn}, \mathrm{Na}$, and $\mathrm{Zn}$, but reduced $\mathrm{P}$ and $\mathrm{S}$ content (Esitken and Turan, 2004). The effects of pre-sowing magnetic treatments on growth and yield of tomato increased significantly $(P<$ 0.05 ) the mean fruit weight, the fruit yield per plant, the fruit yield per area, and the equatorial diameter of fruits in comparison with the controls. Total dry matter was also significantly higher for plants from magnetically treated seeds than controls (De Souza et al., 2006).

In the presence of a static MF, the rhythmic leaflet movements of the plant Desmodium gyrans tended to slowdown. Leaflets moving up and down in a MF of approximately $50 \mathrm{mT}$ flux density increased the period by about $10 \%$ due to a slower motion in the "up" position. Since during this position a rapid change of the extracellular potentials of the pulvinus occurs, it was proposed that the effects could be mediated via the electric processes in the pulvinus tissue (Sharma et al., 2000). Electric process imply ion flux variations. The influence of a high-gradient MF on spatial distribution of ion fluxes along the roots, cytoplasmic streaming, and the processes of plant cell growth connected with intracellular mass and charge transfer was demonstrated (Kondrachuk and Belyavskaya, 2001).

In tomato, a significant delay in the appearance of first symptoms of geminivirus and early blight and a reduced infection rate of early blight were observed in the plants from exposed seeds to increased MFs (De Souza et al., 2006).

Single suspension-cultured plant cells of the Madagascar rosy periwinkle (Catharanthus roseus) and their protoplasts were anchored to a glass plate and exposed to a MF of $302 \pm 8 \mathrm{mT}$ for several hours. Analysis suggested that exposure to the MF roughly tripled the Young's modulus of the newly synthesized cell wall without any lag (Haneda et al., 2006). In vitro tissue cultures of Paulownia tomentosa and Paulownia fortunei exposed to a magnetic flow density of $2.9-4.8 \mathrm{mT}$ and $1 \mathrm{~m} \mathrm{~s}^{-1}$ flow rate for a period of $0,2.2,6.6$, and $19.8 \mathrm{~s}$ showed increased regeneration capability of Paulownia cultures and a shortening of the regeneration time. When the cultures were exposed to a MF with strength of $2.9-4.8 \mathrm{mT}$ for $19.8 \mathrm{~s}$, the regenerated $P$. tomentosa and $P$. fortunei plants dominated the control plants (Yaycili and Alikamanoglu, 2005).

Increase in MF conditions may also affect secondary plant metabolism. The growth of suspension cultures of Taxus chinensis var. mairei and Taxol production were promoted both by a sinusoidal alternating current $\mathrm{MF}(50 \mathrm{~Hz}, 3.5 \mathrm{mT})$ and by a direct current MF (3.5 mT). Taxol production increased rapidly from the 4 th day with the direct current MF but most slowly with the alternating current MF. The maximal yield of Taxol was $490 \mu \mathrm{g}$ $1^{-1}$ with the direct current MF and $425 \mu \mathrm{g} 1^{-1}$ with the alternating current MF after $8 \mathrm{~d}$ of culture, which were, respectively, 1.4-fold and 1.2-fold of that without exposure to a MF (Shang et al., 2004).

The biological impact of MF strengths up to 30 Tesla on transgenic Arabidopsis plants engineered with a stress response gene consisting of the alcohol dehydrogenase (Adh) gene promoter driving the $\beta$-glucuronidase (GUS) gene reporter. Field strengths in excess of about 15 Tesla induce expression of the Adh/GUS transgene in the roots and leaves. From the microarray analyses that surveyed 8000 genes, 114 genes were differentially expressed to a degree greater than 2.5 fold over the control. The data suggest that MF in excess of 15 Tesla have far-reaching effect on the genome. The wide-spread induction of stress-related genes and transcription factors, and a depression of genes associated with cell wall metabolism, are prominent examples. The roles of MF orientation of macromolecules and magnetophoretic effects are possible factors that contribute to the mounting of this response (Paul et al., 2006).

Table 1 summarizes the effects of low and high intensity MF on plants.

\section{THE GEOMAGNETIC FIELD AND PLANT EVOLUTION}

Along with gravity, light, temperature and water availability, the GMF has been present since the beginning of plant evolution. Apart from gravity, all other factors, including the GMF, changed consistently during plant evolution thereby representing important abiotic stress factors eventually contributing to plant diversification and speciation. Mass-extinction events profoundly reshaped Earth's biota during the early and late Mesozoic and terrestrial plants were among the most severely affected groups. Several plant families were wiped out, while some new families emerged and eventually became dominant (Figure 1).

The behavior of the GMF during the Mesozoic and Late Paleozoic, or more precisely between 86 and 276.5 millions of years (Myr), is of particular interest. Its virtual dipole moment (VDM) seems to have been significantly reduced $\left(\approx 4 \times 10^{22} \mathrm{Am}^{2}\right)$ compared to today's values (Shcherbakov et al., 2002). In Earth's history, the GMF exhibited several changes of magnetic polarity, with the so-called geomagnetic reversals or excursions, characterized by persistent times with the same polarity. They occurred some hundred times since Earth formation and the mean time between a reversal and the next one has been estimated around 300,000 years (Figure 2). Because the present normal polarity started around 780,000 years ago and a significant field decay has been occurring during the last 1000 years, an imminent geomagnetic reversal would not be so unexpected (De Santis et al., 2004).

In the course of biological evolution, the fossil record tells us mass extinction occurred several times. One of working hypothesis to explain such mass extinctions is the cease of the GMF when the geomagnetic pole was reversed. Because the strength of the GMF is strongly reduced during polarity transitions, when compared to stable normal or reversed polarities, we recently propose that these variations might be correlated to plant evolution (Occhipinti et al., 2014). We do not have measurable records of GMF polarity reversal before late Jurassic, therefore we can only compare variations of GMF polarity with diversion of families and orders of Angiosperms in the Tertiary and Cretaceous periods. Angiosperms are regarded as one of the greatest terrestrial radiations of recent geological times. The oldest Angiosperm fossils date from the early Cretaceous, $130-136 \mathrm{Myr}$ ago, followed by a rise to ecological dominance in many habitats before the end of the Cretaceous (Soltis et al., 2008). It has been shown that the periods of normal polarity transitions 


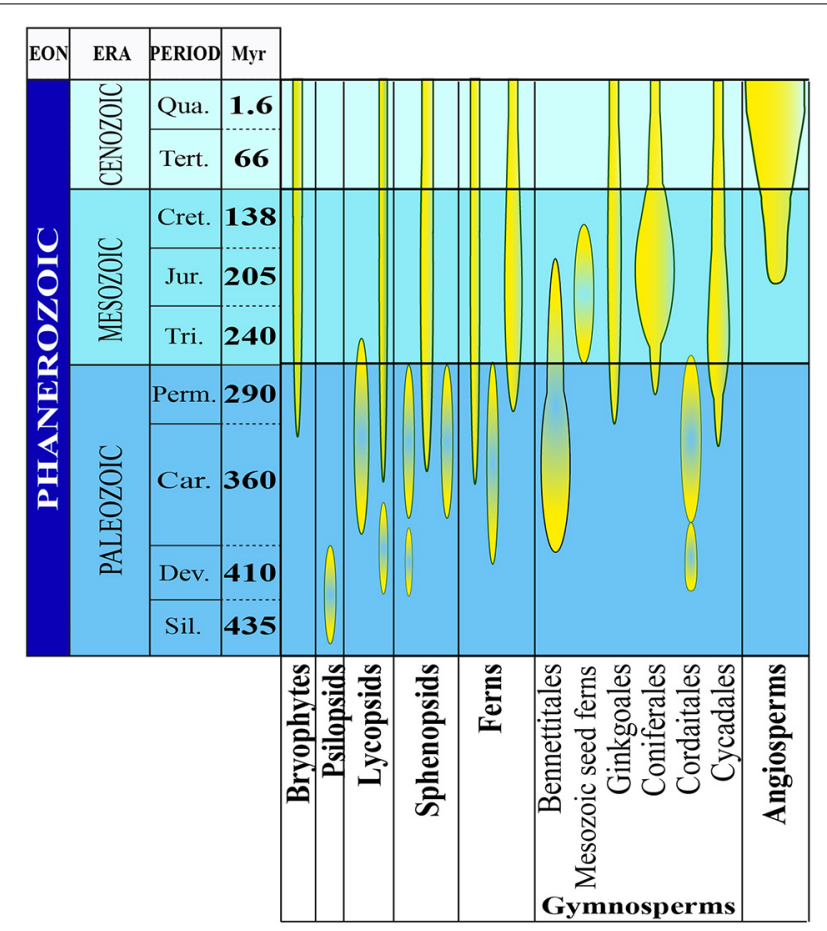

FIGURE 1 | The evolutionary history of plants. The abundance and diversity of plant fossils increase in the Silurian Period where the first macroscopic evidence for land plants has been found. There is evidence for the evolution of several plant groups of the late Devonian and early Carboniferous periods (homosporous ferns and gymnosperms). From the late Devonian through the base of the late Cretaceous period,

gymnosperms underwent dramatic evolutionary radiations and became the dominant group of vascular plants in most habitats. Flowering plants probably also originated during this time, but they did not become a significant part of the fossil flora until the middle of the Cretaceous Period (Modified from Occhipinti et al., 2014).

overlapped with the diversion of most of the familial angiosperm lineages (Figure 2). This correlation appears to be particularly relevant to Angiosperms compared to other plants (Occhipinti et al., 2014).

Patterns of diversification reconstructed onto phylogenetic trees depend on the age of lineages, their intrinsic attributes, and the environments experienced since their origins. Global environments have changed considerably during the history of angiosperm radiation; e.g., the rise of grasses to dominance during the late Tertiary has been linked to global cooling and drying. The greater incidence of high-energy particles, and direct effects of magnetism on biological system during reversals period might contribute to alteration that eventually led to mass extinction. Because plants, in general, do not change their orientation once germinated, there might be distinctive action of the terrestrial magnetism on the growth and physiology of plants (Yamashita et al., 2004). Magnetoreception might be a driving force contributing to plant evolution, but in order to prove such hypothesis we should be able to demonstrate that some plant genes are affected by MF reversals.

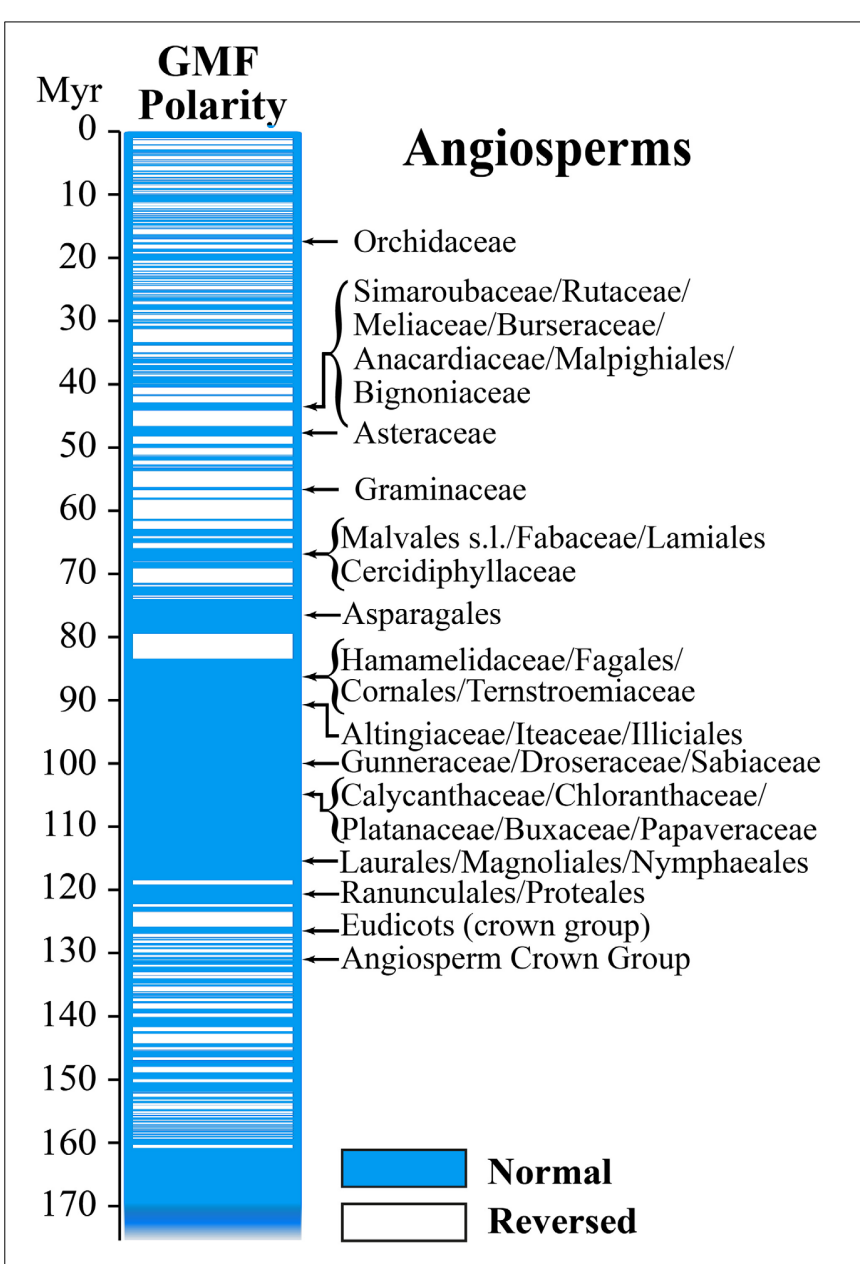

FIGURE 2 | Geomagnetic field reversals and Angiosperm evolution. In the direct comparison of GMF polarity and diversion of Angiosperms it is interesting to note that most of the diversion occurred during periods of normal magnetic polarity (Modified from Occhipinti et al., 2014).

\section{POSSIBLE MECHANISMS OF MAGNETORECEPTION}

For a number of years laboratory studies on the biological effects of MF have demonstrated that the fields can produce or alter a wide range of phenomena. Explaining the diversity of the reported effects is a central problem. In recent years, the following types of physical processes or models underlying hypothetically primary mechanisms of the interaction of MF responses in biological systems have been proposed: (a) classical and quantum oscillator models; (b) cyclotron resonance model; (c) interference of quantum states of bound ions and electrons; (d) coherent quantum excitations; (e) biological effects of torsion fields accompanying MF; (f) biologically active metastable states of liquid water; (g) free-radical reactions and other "spin" mechanisms; (h) parametric resonance model; (i) stochastic resonance as an amplifier mechanism in magnetobiology and other random processes; (j) phase transitions in biophysical systems displaying liquid crystal ordering; ( $\mathrm{k}$ ) bifurcation behavior of solutions of nonlinear chemical kinetics equations; (l) radio-technical models, in which biological structures and tissues are portrayed as equivalent electric circuits and; (m) macroscopic charged vortices in 


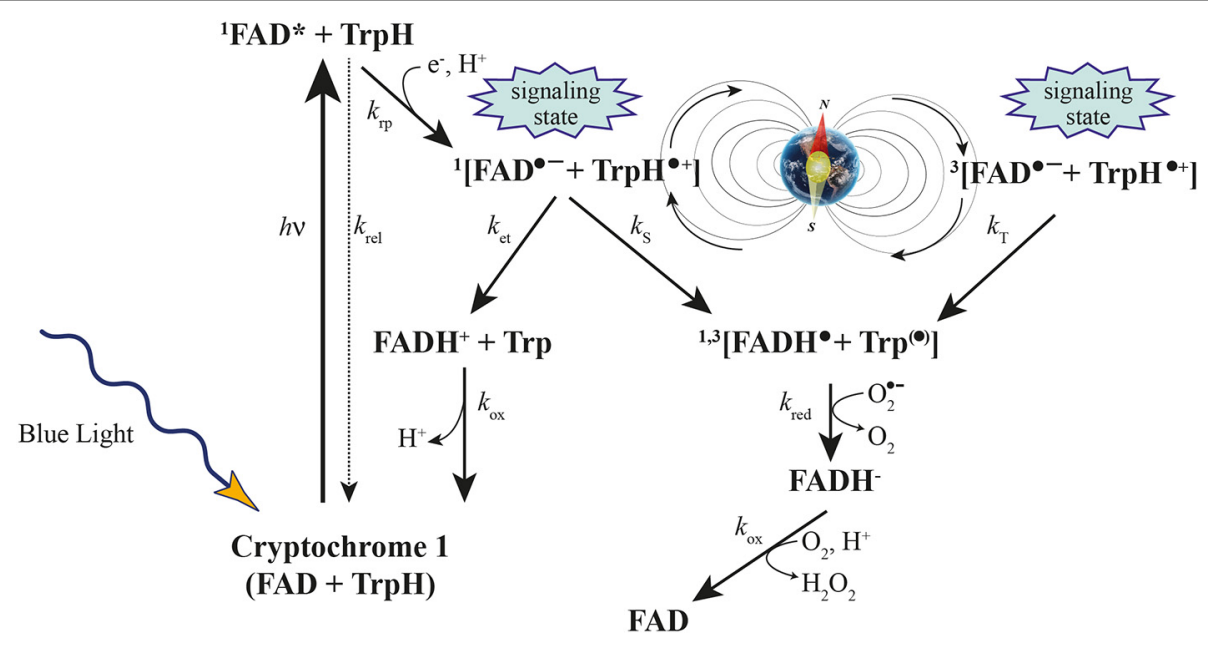

FIGURE 3 | Cryptochrome activation and inactivation reactions. Blue light activates cryptochrome through absorbing a photon by the flavin cofactor. FAD becomes promoted to an excited FAD* state and receives an electron from a nearby tryptophan, leading to the formation of the [FADH• + Trp $\bullet$ radical pair, which exists in singlet
(1) and triplet (3) overall electron spin states by coherent geomagnetic field-dependent interconversions. Under aerobic conditions, FADH• slowly reverts back to the initial inactive FAD state through the also inactive $\mathrm{FADH}^{-}$state of the flavin cofactor (Modified from Occhipinti et al., 2014). cytoplasm. Furthermore, mechanisms combining these concepts and models cannot be excuded (Belyavskaya, 2004).

Observation of resonance effects at specific frequencies, combined with new theoretical considerations and calculations, indicate that birds use a radical pair with special properties that is optimally designed as a receptor in a biological compass. This radical pair design might be realized by cryptochrome photoreceptors if paired with molecular oxygen as a reaction partner (Ritz et al., 2009, 2010). Therefore, several considerations have suggested that cryptochromes are likely to be the primary sensory molecules of the light-dependent magnetodetection mechanism, which has been suggested to be radical pair based (Liedvogel and Mouritsen, 2010).

In plants, cryptochromes control different aspects of growth and development, i.e., involvement in de-etiolation responses such as inhibition of hypocotyl growth (Ahmad and Cashmore, 1993; Lin, 2002), anthocyanin accumulation (Ahmad et al., 1995) leaf and cotyledon expansion (Cashmore et al., 1999; Lin, 2002), transitions to flowering (El-Assal et al., 2003) or regulation of blue-light regulated genes (Jiao et al., 2003). In Arabidopsis, cryptochromes are encoded by two similar genes, cryl and cry2. CRY2 protein levels in seedlings decrease rapidly upon illumination by blue light, presumably as a result of protein degradation of the light-activated form of the receptor (Ahmad et al., 2007). Like photolyases, plant cryptochromes undergo a light-dependent electron transfer reaction, known as photoactivation, that leads to photoreduction of the flavin cofactor, FAD (Giovani et al., 2003).

Particular attention has been paid to the potential role of cryptochrome as a plant magnetosensor (Ahmad and Cashmore, 1993; Ang et al., 1998; Chattopadhyay et al., 1998; Mockler et al., 1999; Lin, 2002; El-Assal et al., 2003; Giovani et al., 2003; Jiao et al., 2003; Zeugner et al., 2005; Ahmad et al., 2007; Bouly et al., 2007; Kleine et al., 2007; Solov'yov et al., 2008; Harris et al., 2009;
Liedvogel and Mouritsen, 2010; Ritz et al., 2010; Solov'yov and Schulten, 2012).

Experiments on Arabidopsis have suggested that magnetic intensity affects cryptochrome-dependent growth responses (Ahmad et al., 2007). But, as discussed above, these reported cryptochrome-mediated MF effects on plant growth could not be replicated in an independent study (Harris et al., 2009). These findings would be very important, if they turn out to exist and be independently replicable, since even though magnetic responses do not seem biologically relevant for the plant, they would show in principle that biological tissue is sensitive to the MF responses that are linked to cryptochrome-dependent signaling pathways. They could thus confirm the ability of cryptochrome to mediate MF responses (Liedvogel and Mouritsen, 2010).

The claimed magnetosensitive responses can best be explained by the radical pair model, as Arabidopsis cryptochromes form radical pairs after photoexcitation (Giovani et al., 2003; Zeugner et al., 2005; Bouly et al., 2007) and these experiments might reflect common physical properties of photoexcited cryptochromes in both plants and animals.

The radical-pair mechanism is currently the only physically plausible mechanism by which magnetic interactions that are orders of magnitude weaker than the average thermal energy, $k_{\mathrm{B}} \mathrm{T}$, can affect chemical reactions. The kinetics and quantum yields of photo-induced flavin-tryptophan radical pairs in cryptochrome are indeed magnetically sensitive and cryptochrome is a good candidate as a chemical magnetoreceptor. Cryptochromes have also attracted attention as potential mediators of biological effects of ELF EMFs and possess properties required to respond to Earth-strength (approximately $50 \mu \mathrm{T}$ ) fields at physiological temperatures (Maeda et al., 2012).

Recently, a combination of quantum biology and molecular dynamics simulations on plant cryptochrome has demonstrated that after photoexcitation a radical pair forms, becomes stabilized 
through proton transfer, and decays back to the protein's resting state on time scales allowing the protein, in principle, to act as a radical pair-based magnetic sensor (Solov'yov and Schulten, 2012 and references therein) (Figure 3). Furthermore, the elimination of the local GMF weakens the inhibition of Arabidopsis hypocotyl growth by white light, and delays flowering time. The expression changes of three Arabidopsis cryptochrome-signalingrelated genes, (PHYB, CO, and FT) suggest that the effects of a near-null MF are cryptochrome-related, which may be revealed by a modification of the active state of cryptochrome and the subsequent signaling cascade plant cryptochrome has been suggested to act as a magnetoreceptor (Xu et al., 2012).

\section{CONCLUSION AND PERSPECTIVES}

Revealing the relationships between MF and plant responses is becoming more and more important as new evidence reveals the ability of plants to perceive and respond quickly to varying MF by altering their gene expression and phenotype. The recent implications of MF reversal with plant evolution opens new horizons not only in plant science but also to the whole biosphere, from the simplest organisms to human beings.

Magnetotactic bacteria are a diverse group of microorganisms with the ability to orient and migrate along GMF lines (Yan et al., 2012); the avian magnetic compass has been well-characterized in behavioral tests (Ritz et al., 2009); magnetic alignment, which constitutes the simplest directional response to the GMF, has been demonstrated in diverse animals including insects, amphibians, fish, and mammals (Begall et al., 2013); concerns of possible biological effects of environmental EMFs on the basis of the energy required to rotate the small crystals of biogenic magnetite that have been discovered in various human tissues have been discussed (Kobayashi and Kirschvink, 1995). The overall picture is thus a general effect of GMF on life forms.

Life evolved on Earth along changes in the GMF life-history. Any other environment lacking a GMF is expected to generate reactions in living organisms. These concerns becomes urgent questions in light of planned long-term flights to other planets (Belyavskaya, 2004). Understanding GMF effects on life will provide the fundamental background necessary to understand evolution of life forms in our planet and will help us to develop scientific recommendations for design of lifesupport systems and their biotic components for future space exploration.

\section{ACKNOWLEDGMENT}

This work was supported by the Department of Life Sciences and Systems Biology research funds.

\section{REFERENCES}

Abe, K., Fujii, N., Mogi, I., Motokawa, M., and Takahashi, H. (1997). Effect of a high magnetic field on plant. Biol. Sci. Space 11, 240-247.

Ahmad, M., and Cashmore, A. R. (1993). Hy4 gene of a. thaliana encodes a protein with characteristics of a blue-light photoreceptor. Nature 366, 162-166. doi: $10.1038 / 366162 \mathrm{a} 0$

Ahmad, M., Galland, P., Ritz, T., Wiltschko, R., and Wiltschko, W. (2007). Magnetic intensity affects cryptochrome-dependent responses in Arabidopsis thaliana. Planta 225, 615-624. doi: 10.1007/s00425-006-0383-0
Ahmad, M., Lin, C. T., and Cashmore, A. R. (1995). Mutations throughout an Arabidopsis blue-light photoreceptor impair blue-light-responsive anthocyanin accumulation and inhibition of hypocotyl elongation. Plant J. 8, 653-658. doi: 10.1046/j.1365-313X.1995.08050653.x

Aksenov, S. I., Bulychev, A. A., Grunina, T. Y., and Turovetskii, V. B. (2000). Effect of low-frequency magnetic field on esterase activity and $\mathrm{pH}$ changes near the wheat germ during imbibition of seeds. Biofizika 45, 737-745.

Aleman, E. I., Mbogholi, A., Boix, Y. F., Gonzalez-Ohnedo, J., and Chalfun, A. (2014). Effects of EMFs on some biological parameters in coffee plants (Coffea arabica L.) obtained by in vitro propagation. Polish J. Environ. Stud. 23, 95-101.

Alexander, M. P., and Ganeshan, S. (1990). Electromagnetic field-induced in vitro pollen germination and tube growth. Curr. Sci. 59, 276-277.

Anand, A., Nagarajan, S., Verma, A., Joshi, D., Pathak, P., and Bhardwaj, J. (2012). Pre-treatment of seeds with static magnetic field ameliorates soil water stress in seedlings of maize (Zea mays L.). Indian J. Biochem. Biophys. 49, 63-70.

Ang, L. H., Chattopadhyay, S., Wei, N., Oyama, T., Okada, K., Batschauer, A., et al. (1998). Molecular interaction between COP1 and HY5 defines a regulatory switch for light control of Arabidopsis development. Mol. Cell 1, 213-222. doi: 10.1016/S1097-2765(00)80022-2

Baby, S. M., Narayanaswamy, G. K., and Anand, A. (2011). Superoxide radical production and performance index of Photosystem II in leaves from magnetoprimed soybean seeds. Plant Signal. Behav. 6, 1635-1637. doi: 10.4161/psb.6.11.17720

Baum, J. W., and Nauman, C. H. (1984). Influence of strong magnetic fields on genetic endpoints in Tradescantia tetrads and stamen hairs. Environ. Mutagen. 6, 49-58. doi: 10.1002/em.2860060107

Begall, S., Malkemper, E. P., Cerveny, J., Nemec, P., and Burda, H. (2013). Magnetic alignment in mammals and other animals. Mammal. Biol. 78, 10-20. doi: 10.1016/j.mambio.2012.05.005

Belov, K. P., and Bochkarev, N. G. (1983). Magnetism on the Earth and in Space. Moskow: Nauka.

Belyavskaya, N. A. (2001). Ultrastructure and calcium balance in meristem cells of pea roots exposed to extremely low magnetic fields. Adv. space Res. 28, 645-650. doi: 10.1016/S0273-1177(01)00373-8

Belyavskaya, N. A. (2004). Biological effects due to weak magnetic field on plants. Adv. Space Res. 34, 1566-1574. doi: 10.1016/j.asr.2004.01.021

Betti, L., Trebbi, G., Fregola, F., Zurla, M., Mesirca, P., Brizzi, M., et al. (2011). Weak static and extremely low frequency magnetic fields affect in vitro pollen germination. Sci. World J. 11, 875-890. doi: 10.1100/tsw.2011.83

Bhardwaj, J., Anand, A., and Nagarajan, S. (2012). Biochemical and biophysical changes associated with magnetopriming in germinating cucumber seeds. Plant Physiol. Biochem. 57, 67-73. doi: 10.1016/j.plaphy.2012.05.008

Bilalis, D. J., Katsenios, N., Efthimiadou, A., and Karkanis, A. (2012). Pulsed electromagnetic field: an organic compatible method to promote plant growth and yield in two corn types. Electromagn. Biol. Med. 31, 333-343. doi: $10.3109 / 15368378.2012 .661699$

Bittl, R., and Weber, S. (2005). Transient radical pairs studied by timeresolved EPR. Biochim. Biophys. Acta-Bioenerg. 1707, 117-126. doi: 10.1016/j.bbabio.2004.03.012

Boe, A. A., and Salunkhe, D. K. (1963). Effects of magnetic fields on tomato ripening. Nature 199, 91-92. doi: 10.1038/199091a0

Bogatina, N. I., Verkin, B. I., and Kordyum, V. A. (1978). Effect of permanent magnetic fields with different intensities on the wheat growth rate. Dokl. Akad. Nauk Ukr. SSR Ser. B. 4, 352-356.

Bouly, J. P., Schleicher, E., Dionisio-Sese, M., Vandenbussche, F., Van Der Straeten, D., Bakrim, N., et al. (2007). Cryptochrome blue light photoreceptors are activated through interconversion of flavin redox states. J. Biol. Chem. 282, 9383-9391. doi: 10.1074/jbc.M609842200

Cakmak, T., Cakmak, Z. E., Dumlupinar, R., and Tekinay, T. (2012). Analysis of apoplastic and symplastic antioxidant system in shallot leaves: impacts of weak static electric and magnetic field. J. Plant Physiol. 169, 1066-1073. doi: 10.1016/j.jplph.2012.03.011

Cakmak, T., Dumlupinar, R., and Erdal, S. (2010). Acceleration of germination and early growth of wheat and bean seedlings grown under various magnetic field and osmotic conditions. Bioelectromagnetics 31, 120-129. doi: 10.1002/bem.20537

Carbonell, M. V., Florez, M., Martinez, E., Maqueda, R., and Amaya, J. (2011). Study of stationary magnetic fields on initial growth of pea (Pisum sativum L.) seeds. Seed Sci. Technol. 39, 673-679. doi: 10.15258/sst.2011.39.3.15 
Cashmore, A. R., Jarillo, J. A., Wu, Y. J., and Liu, D. M. (1999). Cryptochromes: blue light receptors for plants and animals. Science 284, 760-765. doi: 10.1126/science.284.5415.760

Chattopadhyay, S., Ang, L. H., Puente, P., Deng, X. W., and Wei, N. (1998). Arabidopsis bZIP protein HY5 directly interacts with light-responsive promoters in mediating light control of gene expression. Plant Cell 10, 673-683. doi: 10.1105/tpc.10.5.673

Chen, Y.P., Li, R., and He, J. M. (2011). Magnetic field can alleviate toxicological effect induced by cadmium in mungbean seedlings. Ecotoxicology 20, 760-769. doi: 10.1007/s10646-011-0620-6

De Santis, A., Tozzi, R., and Gaya-Pique, L. R. (2004). Information content and Kentropy of the present geomagnetic field. Earth Planet. Sci. Lett. 218, 269-275. doi: 10.1016/S0012-821X(03)00681-2

De Souza, A., Garcia, D., Sueiro, L., Gilart, F., Porras, E., and Licea, L. (2006). Presowing magnetic treatments of tomato seeds increase the growth and yield of plants. Bioelectromagnetics 27, 247-257. doi: 10.1002/bem.20206

De Souza, A., Sueiro, L., Garcia, D., and Porras, E. (2010). Extremely low frequency non-uniform magnetic fields improve tomato seed germination and early seedling growth. Seed Sci. Technol. 38, 61-72. doi: 10.15258/sst.2010.38.1.06

El-Assal, S. E. D., onso-Blanco, C., Peeters, A. J. M., Wagemaker, C., Weller, J. L., and Koornneef, M. (2003). The role of cryptochrome 2 in flowering in Arabidopsis. Plant Physiol. 133, 1504-1516. doi: 10.1104/pp.103.029819

Esitken, A., and Turan, M. (2004). Alternating magnetic field effects on yield and plant nutrient element composition of strawberry (Fragaria $x$ ananassa cv. Camarosa). Acta Agric. Scand. Sect. B Soil Plant Sci. 54, 135-139. doi: $10.1080 / 09064710310019748$

Firn, R. D., and Digby, J. (1997). Solving the puzzle of gravitropism-Has a lost piece been found? Planta 203, S159-S163. doi: 10.1007/PL00008104

Fischer, G., Tausz, M., Kock, M., and Grill, D. (2004). Effects of weak 162/3 Hz magnetic fields on growth parameters of young sunflower and wheat seedlings. Bioelectromagnetics 25, 638-641. doi: 10.1002/bem.20058

Florez, M., Carbonell, M. V., and Martinez, E. (2004). Early sprouting and first stages of growth of rice seeds exposed to a magnetic field. Electromagn. Biol. Med. 23, 157-166. doi: 10.1081/LEBM-200042316

Florez, M., Carbonell, M. V., and Martinez, E. (2007). Exposure of maize seeds to stationary magnetic fields: effects on germination and early growth. Environ. Exp. Bot. 59, 68-75. doi: 10.1016/j.envexpbot.2005.10.006

Galland, P., and Pazur, A. (2005). Magnetoreception in plants. J. Plant Res. 118 371-389. doi: 10.1007/s10265-005-0246-y

Giovani, B., Byrdin, M., Ahmad, M., and Brettel, K. (2003). Light-induced electron transfer in a cryptochrome blue-light photoreceptor. Nat. Struct. Biol. 10 , 489-490. doi: 10.1038/nsb933

Haghighat, N., Abdolmaleki, P., Ghanati, F., Behmanesh, M., and Payez, A. (2014) Modification of catalase and MAPK in Vicia faba cultivated in soil with high natural radioactivity and treated with a static magnetic field. J. Plant Physiol. 171, 99-103. doi: 10.1016/j.jplph.2013.10.019

Haneda, T., Fujimura, Y., and Iino, M. (2006). Magnetic field exposure stiffens regenerating plant protoplast cell walls. Bioelectromagnetics 27, 98-104. doi: 10.1002/bem.20169

Harris, S. R., Henbest, K. B., Maeda, K., Pannell, J. R., Timmel, C. R., Hore, P. J., et al. (2009). Effect of magnetic fields on cryptochrome-dependent responses in Arabidopsis thaliana. J. R. Soc. Interface 6, 1193-1205. doi: 10.1098/rsif.2008.0519

Hasenstein, K. H., John, S., Scherp, P., Povinelli, D., and Mopper, S. (2013). Analysis of magnetic gradients to study gravitropism. Am. J. Bot. 100, 249-255. doi: 10.3732/ajb.1200304

Hasenstein, K. H., and Kuznetsov, O. A. (1999). The response of lazy-2 tomato seedlings to curvature-inducing magnetic gradients is modulated by light Planta 208, 59-65. doi: 10.1007/s004250050534

Herranz, R., Manzano, A. I., van Loon, J. J. W. A., Christianen, P. C. M., and Medina, F. J. (2013). Proteomic signature of Arabidopsis cell cultures exposed to magnetically induced hyper- and microgravity environments. Astrobiology 13, 217-224. doi: 10.1089/ast.2012.0883

Iimoto, M., Watanabe, K., and Fujiwara, K. (1998). Effects of magnetic flux density and direction of the magnetic field on growth and $\mathrm{CO} 2$ exchange rate of potato plantlets in vitro. Acta Hortic. 440, 606-610.

Iqbal, M., Muhammad, D., Hag, Z. U., Jamil, Y., and Ahmad, M. (2012). Effect of pre-sowing magnetic field treatment to garden pea (Pisum sativum L.) seed on germination and seedling growth. Pak. J. Bot. 44, 1851-1856.
Izmaylov, A. F., Tully, J. C., and Frisch, M. J. (2009). Relativistic interactions in the radical pair model of magnetic field sense in CRY-1 protein of Arabidopsis thaliana. J. Phys. Chem. A 113, 12276-12284. doi: 10.1021/ jp900357f

Javed, N., Ashraf, M., Akram, N. A., and Al-Qurainy, F. (2011). Alleviation of adverse effects of drought stress on growth and some potential physiological attributes in maize (Zea mays L.) by seed electromagnetic treatment. Photochem. Photobiol. 87, 1354-1362. doi: 10.1111/j.1751-1097.2011.00990.x

Jiao, Y., Yang, H., Ma, L., Sun, N., Yu, H., Liu, T., et al. (2003). A genomewide analysis of blue-light regulation of Arabidopsis transcription factor gene expression during seedling development. Plant Physiol. 133, 1480-1493. doi: 10.1104/pp.103.029439

Jouni, F. J., Abdolmaleki, P., and Ghanati, F. (2012). Oxidative stress in broad bean (Vicia faba L.) induced by static magnetic field under natural radioactivity. Mutat. Res. 741, 116-121. doi: 10.1016/j.mrgentox.2011.11.003

Jovanic, B. R., and Sarvan, M. Z. (2004). Permanent magnetic field and plant leaf temperature. Electromagn. Biol. Med. 23, 1-5. doi: 10.1081/JBC-120037861

Kleine, T., Kindgren, P., Benedict, C., Hendrickson, L., and Strand, A. (2007). Genome-wide gene expression analysis reveals a critical role for CRYPTOCHROME1 in the response of arabidopsis to high irradiance. Plant Physiol. 144, 1391-1406. doi: 10.1104/pp.107.098293

Kobayashi, A., and Kirschvink, J. L. (1995). Magnetoreception and electromagnetic field effects: sensory perception of the geomagnetic field in animals and humans. Am. Chem. Soc. 250, 367-394. doi: 10.1021/ba-1995-0250.ch021

Kobayashi, M., Soda, N., Miyo, T., and Ueda, Y. (2004). Effects of combined DC and AC magnetic fields on germination of hornwort seeds. Bioelectromagnetics 25, 552-559. doi: 10.1002/bem.20032

Kondrachuk, A., and Belyavskaya, N. (2001). The influence of the HGMF on masscharge transfer in gravisensing cells. J. Gravit Physiol. 8, 37-38.

Kordyum, E. L., Bogatina, N. I., Kalinina, Y. M., and Sheykina, N. V. (2005). A weak combined magnetic field changes root gravitropism. Adv. Space Res. 36, 1229-1236. doi: 10.1016/j.asr.2005.05.103

Krylov, A., and Tarakonova, G. A. (1960). Plant physiology. Fiziol. Rost. 7, 156.

Kuznetsov, O. A., and Hasenstein, K. H. (1996). Intracellular magnetophoresis of amyloplasts and induction of root curvature. Planta 198, 87-94. doi: 10.1007/BF00197590

Kuznetsov, O. A., and Hasenstein, K. H. (1997). Magnetophoretic induction of curvature in coleoptiles and hypocotyls. J. Exp. Bot. 48, 1951-1957. doi: 10.1093/jxb/48.11.1951

Kuznetsov, O. A., Schwuchow, J., Sack, F. D., and Hasenstein, K. H. (1999). Curvature induced by amyloplast magnetophoresis in protonemata of the moss Ceratodon purpureus. Plant Physiol. 119, 645-650. doi: 10.1104/pp.119.2.645

Lebedev, S. I., Baranskiy, P. I., Litvinenko, L. G., and Shiyan, L. T. (1977). Barley growth in superweak magnetic field. Electron. Treat. Mater. 3, 71-73.

Li, A. (2000). Effect of gradient magnetic field on growth of stem pearls of Dioscorea opposita during seedling stage. Zhongguo Zhong Yao Za Zhi 25, 341-343.

Liedvogel, M., and Mouritsen, H. (2010). Cryptochromes-a potential magnetoreceptor: what do we know and what do we want to know? J. R. Soc. Interface 7, S147-S162. doi: 10.1098/rsif.2009.0411.focus

Lin, C. T. (2002). Blue light receptors and signal transduction. Plant Cell 14, S207-S225. doi: 10.1105/tpc.000646

Maeda, K., Robinson, A. J., Henbest, K. B., Hogben, H. J., Biskup, T., Ahmad, M., et al. (2012). Magnetically sensitive light-induced reactions in cryptochrome are consistent with its proposed role as a magnetoreceptor. Proc. Natl. Acad. Sci. U.S.A. 109, 4774-4779. doi: 10.1073/pnas.1118959109

Mahajan, T. S., and Pandey, O. P. (2014). Magnetic-time model at off-season germination. Int. Agrophys. 28, 57-62. doi: 10.2478/intag-2013-0027

Manzano, A. I., Larkin, O. J., Dijkstra, C. E., Anthony, P., Davey, M. R., Eaves, L., et al. (2013). Meristematic cell proliferation and ribosome biogenesis are decoupled in diamagnetically levitated Arabidopsis seedlings. BMC Plant Biol. 13:124. doi: 10.1186/1471-2229-13-124

Martinez, E., Carbonell, M. V., and Amaya, J. M. (2000). A static magnetic field of $125 \mathrm{mT}$ stimulates the initial growth stages of barley (Hordeum vulgare L.) Electromagn. Magnetobiol. 19, 271-277.

Minorsky, P. V. (2007). Do geomagnetic variations affect plant function? J. Atmos. Solar-Terrest. Phys. 69, 1770-1774. doi: 10.1016/j.jastp.2006.12.004

Mockler, T. C., Guo, H. W., Yang, H. Y., Duong, H., and Lin, C. T. (1999) Antagonistic actions of Arabidopsis cryptochromes and phytochrome B in the regulation of floral induction. Development 126, 2073-2082. 
Nanushyan, E. R., and Murashov, V. V. (2001). "Plant meristem cell response to stress factors of the geomagnetic field (GMF) fluctuations," in Plant Under Environmental Stress (Moscow: Friendship University of Russia), 204-205.

Naz, A., Jamil, Y., ul Haq, Z., Iqbal, M., Ahmad, M. R., Ashraf, M. I., et al. (2012). Enhancement in the germination, growth and yield of Okra (Abelmoschus esculentus) using pre-sowing magnetic treatment of seeds. Indian J. Biochem. Biophys. 49, 211-214.

Nedukha, O., Kordyum, E., Bogatina, N., Sobol, M., Vorobyeva, T., and Ovcharenko, Y. (2007). The influence of combined magnetic field on the fusion of plant protoplasts. J. Gravit. Physiol. 14, 117-118.

Negishi, Y., Hashimoto, A., Tsushima, M., Dobrota, C., Yamashita, M., and Nakamura, T. (1999). Growth of pea epicotyl in low magnetic field implication for space research. Adv. Space Res. 23, 2029-2032. doi: 10.1016/S02731177(99)00342-7

Novitskaya, G. V., Molokanov, D., Kocheshkova, T., and Novitskii, Y. I (2010). Effect of weak constant magnetic field on the composition and content of lipids in radish seedlings at various temperatures. Russ. J. Plant Physiol. 57, 52-61. doi: 10.1134/S1021443710010073

Novitskii, Y. I., Novitskaya, G. V., and Serdyukov, Y. A. (2014). Lipid utilization in radish seedlings as affected by weak horizontal extremely low frequency magnetic field. Bioelectromagnetics 35, 91-99. doi: 10.1002/bem.21818

Occhipinti, A., De Santis, A., and Maffei, M. E. (2014). Magnetoreception: an unavoidable step for plant evolution? Trends Plant Sci. 19, 1-4. doi: 10.1016/j.tplants.2013.10.007

Paul, A. L., Ferl, R. J., and Meisel, M. W. (2006). High magnetic field induced changes of gene expression in arabidopsis. Biomagn. Res. Technol. 4, 7. doi: 10.1186/1477-044X-4-7

Payez, A., Ghanati, F., Behmanesh, M., Abdolmaleki, P., Hajnorouzi, A., and Rajabbeigi, E. (2013). Increase of seed germination, growth and membrane integrity of wheat seedlings by exposure to static and a 10-KHz electromagnetic field. Electromagn. Biol. Med. 32, 417-429. doi: 10.3109/15368378.2012.735625

Phirke, P. S., Kubde, A. B., and Umbarkar, S. P. (1996). The influence of magnetic field on plant growth. Seed Sci. Technol. 24, 375-392.

Pittman, U. J. (1962). Growth reaction and magnetotropism in roots of winter wheat (Kharkov 22 M.C.). Can. J. Plant Sci. 42, 430. doi: 10.4141/cjps62-070

Pittman, U. J. (1963). Magnetism and plant growth. I. Effect on germination and early growth of cereal seeds. Can. J. Plant Sci. 43, 513-518. doi: 10.4141/cjps63104

Poinapen, D., Brown, D. C. W., and Beeharry, G. K. (2013a). Seed orientation and magnetic field strength have more influence on tomato seed performance than relative humidity and duration of exposure to non-uniform static magnetic fields. J. Plant Physiol. 170, 1251-1258. doi: 10.1016/j.jplph.2013.04.016

Poinapen, D., Toppozini, L., Dies, H., Brown, D. C. W., and Rheinstadter, M. C. (2013b). Static magnetic fields enhance lipid order in native plant plasma membrane. Soft Matter 9, 6804-6813. doi: 10.1039/c3sm50355k

Polovinkina, E., Kal'yasova, E., Sinitsina, Y., V., and Veselov, A. (2011). Effect of weak pulse magnetic fields on lipid peroxidation and activities of antioxidant complex components in pea chloroplasts. Russ. J. Plant Physiol. 58, 1069-1073. doi: 10.1134/S102144371106015X

Qamili, E., De Santis, A., Isac, A., Mandea, M., Duka, B., and Simonyan, A. (2013). Geomagnetic jerks as chaotic fluctuations of the Earth's magnetic field. Geochem.Geophys.Geosys. 14, 839-850. doi: 10.1029/2012GC004398

Radhakrishnan, R., and Kumari, B. D. R. (2012). Pulsed magnetic field: a contemporary approach offers to enhance plant growth and yield of soybean. Plant Physiol. Biochem. 51, 139-144. doi: 10.1016/j.plaphy.2011.10.017

Radhakrishnan, R., and Kumari, B. D. R. (2013). Influence of pulsed magnetic field on soybean (Glycine max L.) seed germination, seedling growth and soil microbial population. Indian J. Biochem. Biophys. 50, 312-317.

Rajabbeigi, E., Ghanati, F., Abdolmaleki, P., and Payez, A. (2013). Antioxidant capacity of parsley cells (Petroselinum crispum L.) in relation to iron-induced ferritin levels and static magnetic field. Electromagn. Biol. Med. 32, 430-441. doi: 10.3109/15368378.2012.736441

Rakosy-Tican, L., Aurori, C. M., and Morariu, V. V. (2005). Influence of near null magnetic field on in vitro growth of potato and wild Solanum species. Bioelectromagnetics 26, 548-557. doi: 10.1002/bem.20134

Regoli, F., Gorbi, S., Marchella, N., Tedesco, S., and Principato, G. (2005). Pro-oxidant effects of extremely low frequency electromagnetic fields in the land snail Helix aspesa. Free Radic. Biol. Med. 39, 1620-1628. doi: 10.1016/j.freeradbiomed.2005.08.004
Ritz, T., Wiltschko, R., Hore, P. J., Rodgers, C. T., Stapput, K., Thalau, P., et al. (2009). Magnetic compass of birds is based on a molecule with optimal directional sensitivity. Biophys. J. 96, 3451-3457. doi: 10.1016/j.bpj.2008.11.072

Ritz, T., Yoshii, T., Helfrich-Foester, C., and Ahmad, M. (2010). Cryptochrome: a photoreceptor with the properties of a magnetoreceptor? Commun. Integr. Biol. 3, 24-27. doi: 10.4161/cib.3.1.9865

Rochalska, M. (2005). Influence of frequent magnetic field on chlorophyll content in leaves of sugar beet plants. Nukleonika 50, S25-S28.

Rochalska, M. (2008). The influence of low frequency magnetic field upon cultivable plant physiology. Nukleonika 53, S17-S20.

Rochalska, M., and Orzeszko-Rywka, A. (2005). Magnetic field treatment improves seed performance. Seed Sci. Technol. 33, 669-674. doi: 10.15258/sst.2005.33.3.14

Sakhnini, L. (2007). Influence of $\mathrm{Ca}^{2+}$ in biological stimulating effects of AC magnetic fields on germination of bean seeds. J. Magn. Magn. Mater. 310, E1032-E1034. doi: 10.1016/j.jmmm.2006.11.077

Serdyukov, Y., and Novitskii, Y. I. (2013). Impact of weak permanent magnetic field on antioxidant enzyme activities in radish seedlings. Russ. J. Plant Physiol. 60, 69-76. doi: 10.1134/S1021443713010068

Shang, G. M., Wu, J. C., and Yuan, Y. J. (2004). Improved cell growth and Taxol production of suspension-cultured Taxus chinensis var. mairei in alternating and direct current magnetic fields. Biotechnol. Lett. 26, 875-878. doi: 10.1023/B:bile.0000025895.76394.ab

Sharma, V. K., Engelmann, W., and Johnsson, A. (2000). Effects of static magnetic field on the ultradian lateral leaflet movement rhythm in Desmodium gyrans. Z. Naturforsc. 55, 638-642.

Shcherbakov, V. P., Solodovnikov, G. M., and Sycheva, N. K. (2002). Variations in the geomagnetic dipole during the past 400 million years (volcanic rocks). Izvestiya Phys. Solid Earth 38, 113-119.

Shine, M., and Guruprasad, K. (2012). Impact of pre-sowing magnetic field exposure of seeds to stationary magnetic field on growth, reactive oxygen species and photosynthesis of maize under field conditions. Acta Physiol. Plant. 34, 255-265. doi: 10.1007/s11738-011-0824-7

Shine, M., Guruprasad, K., and Anand, A. (2011). Enhancement of germination, growth, and photosynthesis in soybean by pre-treatment of seeds with magnetic field. Bioelectromagnetics 32, 474-484. doi: 10.1002/bem.20656

Shine, M., Guruprasad, K., and Anand, A. (2012). Effect of stationary magnetic field strengths of 150 and $200 \mathrm{mT}$ on reactive oxygen species production in soybean. Bioelectromagnetics 33, 428-437. doi: 10.1002/bem.21702

Solov'yov, I. A., Chandler, D. E., and Schulten, K. (2008). Exploring the possibilities for radical pair effects in cryptochrome. Plant Signal. Behav. 3, 676-677. doi: 10.4161/psb.3.9.5809

Solov'yov, I. A., and Schulten, K. (2012). Reaction kinetics and mechanism of magnetic field effects in cryptochrome. J. Phys. Chem. B 116, 1089-1099. doi: 10.1021/jp209508y

Soltis, D. E., Bell, C. D., Kim, S., and Soltis, P. S. (2008). Origin and early evolution of angiosperms. Ann. N.Y. Acad. Sci. 1133, 3-25. doi: 10.1196/annals.1438.005

Stange, B. C., Rowland, R. E., Rapley, B. I., and Podd, J. V. (2002). ELF magnetic fields increase amino acid uptake into Vicia faba L. roots and alter ion movement across the plasma membrane. Bioelectromagnetics 23, 347-354. doi: 10.1002/bem.10026

Turker, M., Temirci, C., Battal, P., and Erez, M. E. (2007). The effects of an artificial and static magnetic field on plant growth, chlorophyll and phytohormone levels in maize and sunflower plants. Phyton Ann. Rei Botan. 46, 271-284.

Vanderstraeten, J., and Burda, H. (2012). Does magnetoreception mediate biological effects of power-frequency magnetic fields? Sci. Total. Environ. 417, 299-304. doi: 10.1016/j.scitotenv.2011.08.071

Vashisth, A., and Nagarajan, S. (2008). Exposure of seeds to static magnetic field enhances germination and early growth characteristics in chickpea (Cicer arietinum L.). Bioelectromagnetics 29, 571-578. doi: 10.1002/bem.20426

Vashisth, A., and Nagarajan, S. (2010). Effect on germination and early growth characteristics in sunflower (Helianthus annuus) seeds exposed to static magnetic field. J. Plant Physiol. 167, 149-156. doi: 10.1016/j.jplph.2009.08.011

Volpe, P. (2003). Interactions of zero-frequency and oscillating magnetic fields with biostructures and biosystems. Photochem. Photobiol. Sci. 2, 637-648. doi: $10.1039 / \mathrm{b} 212636 \mathrm{~b}$

Voznyak, V. M., Ganago, I. B., Moskalenko, A. A., and Elfimov, E. I. (1980). Magnetic field-induced fluorescence changes in chlorophyll-proteins enriched with P-700. Biochim. Biophys. Acta 592, 364-368. doi: 10.1016/00052728(80)90196-6 
Weise, S. E., Kuznetsov, O. A., Hasenstein, K. H., and Kiss, J. Z. (2000). Curvature in Arabidopsis inflorescence stems is limited to the region of amyloplast displacement. Plant Cell Physiol. 41, 702-709. doi: 10.1093/pcp/41.6.702

Xia, L., and Guo, J. (2000). Effect of magnetic field on peroxidase activation and isozyme in Leymus chinensis. Ying Yong Sheng Tai Xue Bao 11, 699-702.

Xu, C., Lv, Y., Chen, C., Zhang, Y., and Wei, S. (2014). Blue light-dependent phosphorylations of cryptochromes are affected by magnetic fields in Arabidopsis. Adv. Space Res. 53, 1118-1124. doi: 10.1016/j.asr.2014.01.033

Xu, C. X., Wei, S. F., Lu, Y., Zhang, Y. X., Chen, C. F., and Song, T. (2013). Removal of the local geomagnetic field affects reproductive growth in Arabidopsis. Bioelectromagnetics 34, 437-442. doi: 10.1002/bem.21788

Xu, C. X., Yin, X., Lv, Y., Wu, C. Z., Zhang, Y. X., and Song, T. (2012). A near-null magnetic field affects cryptochrome-related hypocotyl growth and flowering in Arabidopsis. Adv. Space Res. 49, 834-840. doi: 10.1016/j.asr.2011.12.004

Yamashita, M., Tomita-Yokotani, K., Hashimoto, H., Takai, M., Tsushima, M., and Nakamura, T. (2004). Experimental concept for examination of biological effects of magnetic field concealed by gravity. Adv. Space Res. 34, 1575-1578. doi: 10.1016/j.asr.2004.01.022

Yan, L., Zhang, S., Chen, P., Liu, H., Yin, H., and Li, H. (2012). Magnetotactic bacteria, magnetosomes and their application. Microbiol. Res. 167, 507-519. doi: 10.1016/j.micres.2012.04.002

Yano, A., Ohashi, Y., Hirasaki, T., and Fuliwara, K. (2004). Effects of a $60 \mathrm{~Hz}$ magnetic field on photosynthetic $\mathrm{CO} 2$ uptake and early growth of radish seedlings. Bioelectromagnetics 25, 572-581. doi: 10.1002/bem.20036
Yaycili, O., and Alikamanoglu, S. (2005). The effect of magnetic field on Paulownia tissue cultures. Plant Cell Tiss. Organ Cult. 83, 109-114. doi: 10.1007/s11240005-4852-0

Zeugner, A., Byrdin, M., Bouly, J. P., Bakrim, N., Giovani, B., Brettel, K., et al. (2005). Light-induced electron transfer in Arabidopsis cryptochrome-1 correlates with in vivo function. J. Biol. Chem. 280, 19437-19440. doi: 10.1074/jbc.C500077200

Conflict of Interest Statement: The author declares that the research was conducted in the absence of any commercial or financial relationships that could be construed as a potential conflict of interest.

Received: 05 June 2014; paper pending published: 17 August 2014; accepted: 18 August 2014; published online: 04 September 2014.

Citation: Maffei ME (2014) Magnetic field effects on plant growth, development, and evolution. Front. Plant Sci. 5:445. doi: 10.3389/fpls.2014.00445

This article was submitted to Plant Physiology, a section of the journal Frontiers in Plant Science.

Copyright (c) 2014 Maffei. This is an open-access article distributed under the terms of the Creative Commons Attribution License (CC BY). The use, distribution or reproduction in other forums is permitted, provided the original author(s) or licensor are credited and that the original publication in this journal is cited, in accordance with accepted academic practice. No use, distribution or reproduction is permitted which does not comply with these terms. 